Mariana Amora Cocuzza

\title{
Ablação endometrial com ácido tricloroacético em ratas: estudo histomorfométrico e histológico
}

Dissertação apresentada à Faculdade de Medicina da Universidade de São Paulo para obtenção do título de Mestre em Ciências

Programa de: Obstetrícia e Ginecologia Orientador: Dr. Gustavo Arantes Rosa Maciel

São Paulo 2011 
Dados Internacionais de Catalogação na Publicação (CIP)

Preparada pela Biblioteca da

Faculdade de Medicina da Universidade de São Paulo

Creprodução autorizada pelo autor

Cocuzza, Mariana Amora

Ablação endometrial com ácido tricloroacético em ratas : estudo histomorfométrico e histológico / Mariana Amora Cocuzza. -- São Paulo, 2011.

Dissertação(mestrado)--Faculdade de Medicina da Universidade de São Paulo.

Programa de Obstetrícia e Ginecologia.

Orientador: Gustavo Arantes Rosa Maciel.

Descritores: 1.Técnicas de ablação endometrial 2.Ácido tricloroacético 3.Hemorragia uterina disfuncional 4.Endométrio 5.Abrasão química 6.Ratos 7.Feminino

USP/FM/DBD-029/11 


\section{Dedicatória}


Ao meu marido Marcello, pelo amor, compreensão e suporte incondicional em minha vida;

A minha filha Anita, pela alegria e inspiração;

Ao meu filho Caio, pelo estímulo de viver. 
Agradecimentos 


\section{AGRADECIMENTOS}

- À minha mãe, Eliana, pelo amor, pela minha formação ética e moral, a quem amo, admiro, e é meu exemplo de caráter e superação.

- Ao meu pai, Gil, pelo amor e apoio sempre presentes.

- Ao meu irmão, Pedro, pelo companheirismo, amor e cumplicidade.

- Ao Dr. Gustavo Maciel, amigo e orientador, pela inestimável colaboração e apoio irrestrito.

- A Dra. Ana Paula Torres, pelo apoio, paciência e dedicação ao me ensinar todos os conhecimentos sobre patologia utilizados na elaboração dessa tese.

- Ao Dr. Eduardo Viera da Motta, pela amizade, estímulo e apoio constante durante a elaboração desta tese.

- Ao Prof. Dr. Edmund Baracat, pela orientação, estímulo, exemplo, e por ter permitido a realização deste trabalho.

- A Dra. Adele Lapin, pela amizade, carinho e apoio sempre presentes.

- Aos Prof. Dr. Maurício Simões Abrão, Prof. Dr. José Maria Soares Junior e Dr. Manuel de Jesus Simões, pelas valiosas sugestões durante a aula de qualificação.

- A Maria Luisa Guzzo Valenti, agradeço por me introduzir nas técnicas de laboratório essenciais na realização desse estudo.

- Aos técnicos do biotério central da FMUSP, sou grata pela ajuda e dedicação constante aos cuidados prestados aos animais utilizados nessa pesquisa. 
- A Sra. Claudia Aparecida Vieira, pela ajuda integral durante a pósgraduação.

- Agradeço a todos os integrantes do LIM 58 pelo auxílio à pesquisa concedido a este estudo. 


\section{CONFLITO DE INTERESSE}

Este projeto não apresenta nenhum conflito de interesse.

O desenvolvimento desta pesquisa ocorreu no Laboratório de Ginecologia

Estrutural e Molecular da Disciplina de Ginecologia da Faculdade de Medicina da Universidade de São Paulo - LIM 58. 
Esta tese está de acordo com as seguintes normas, em vigor no momento desta publicação:

Referências: adaptado de International Committee of Medical Journals Editors (Vancouver)

Universidade de São Paulo. Faculdade de Medicina. Serviço de Biblioteca e Documentação. Guia de apresentação de dissertações, teses e monografias. Elaborado por Anneliese Carneiro da Cunha, Maria Julia de A. L. Freddi, Maria F. Crestana, Marinalva de Souza Aragão, Suely Campos Cardoso, Valéria Vilhena. $2^{a}$ ed. São Paulo: Serviço de Biblioteca e Documentação; 2005.

Abreviaturas dos títulos de periódicos de acordo com List of Journals Indexed in Index Medicus 


\section{SUMÁRIO}

Lista de abreviaturas, símbolos e siglas

Lista de Tabelas

Lista de Gráficos

Lista de Figuras

RESUMO

SUMMARY

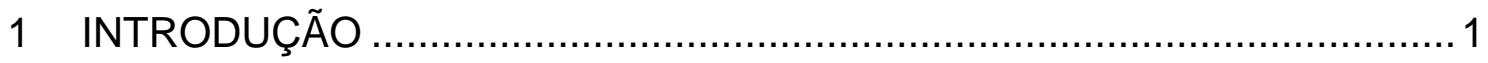

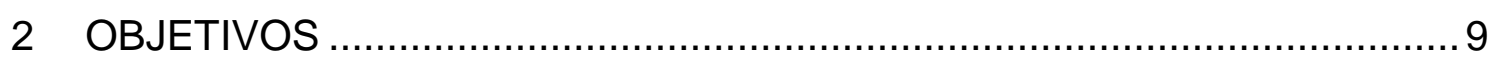

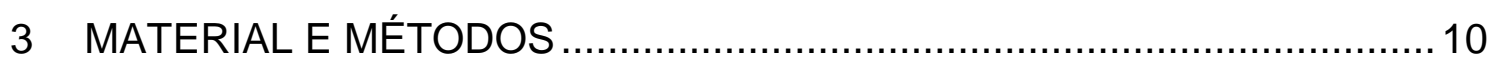

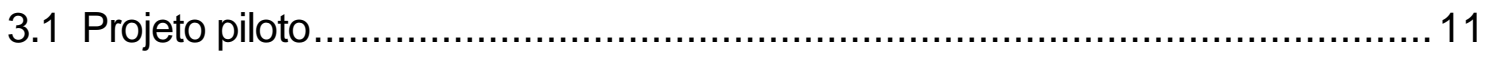

3.1.1 Cálculo do volume de líquido injetado ...................................... 11

3.1.2 Definição da concentração de ácido tricloroacético a ser utilizada ...........12

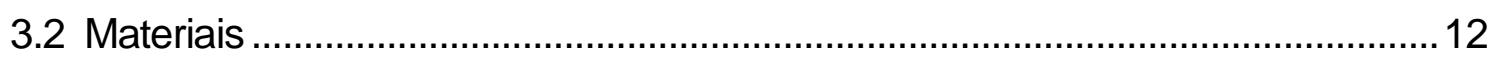

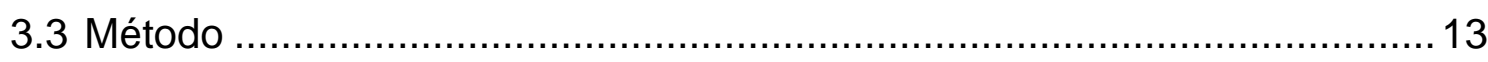

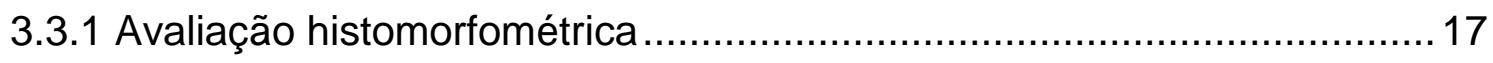

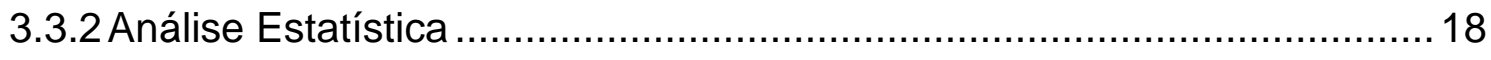

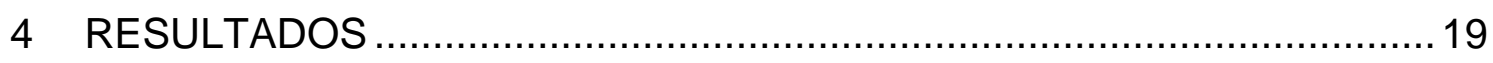

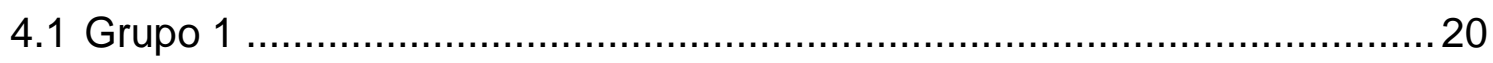

4.1.1 Espessura do epitélio superficial do endométrio.............................21

4.1.2 Espessura do estroma endometrial ......................................... 24

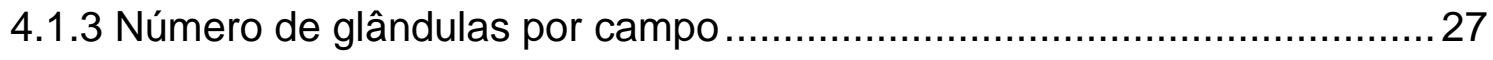

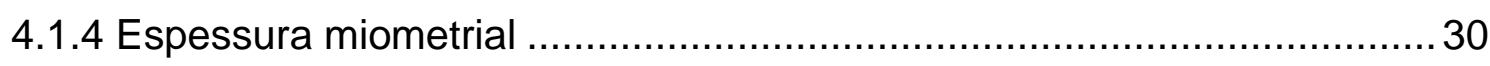


4.2 Grupo 2

4.2.1 Espessura do epitélio superficial do endométrio.....................................37

4.2.2 Espessura do estroma endometrial .................................................. 40

4.2.3 Número de glândulas por campo ......................................................... 43

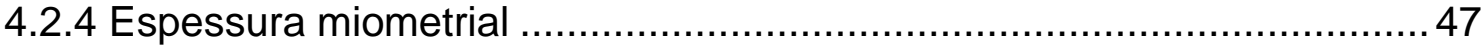

4.3 Avaliação da regeneração endometrial nos Grupo 1 e 2...........................50

4.3.1 Espessura do epitélio superficial do endométrio....................................51

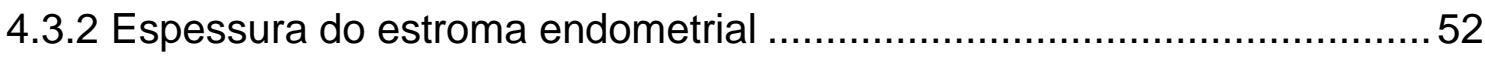

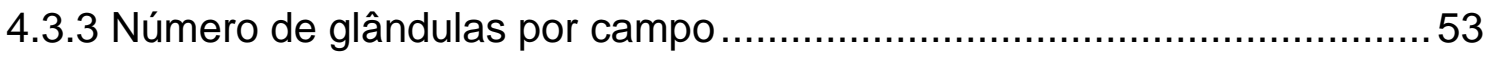

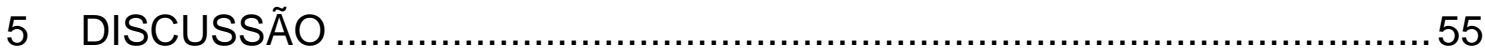

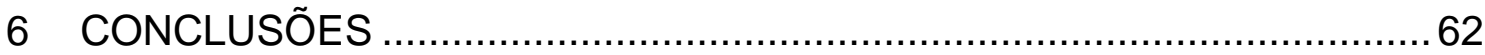

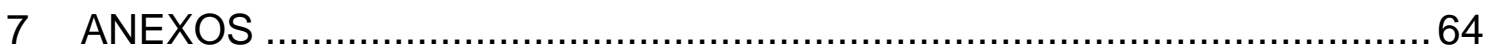

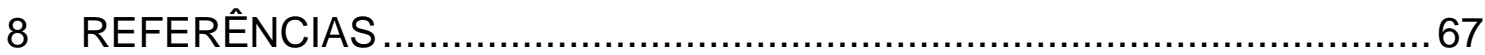




\section{LISTA DE ABREVIATURAS, SÍMBOLOS E SIGLAS}

$$
\begin{array}{ll}
\% & \text { por cento } \\
> & \text { maior que } \\
< & \text { menor que } \\
\mu \mathrm{m} & \text { micrômetro }
\end{array}
$$

ATA ácido tricloroacético

cm centímetro

$\mathrm{CO}_{2}$ dióxido de carbono

et al. e outros

EUA Estados Unidos da América

HE Hematoxilina-Eosina

Kg quilograma

mg miligrama

min minuto

$\mathrm{mL} \quad$ mililitro

mm milímetro

SF soro fisiológico a $0,9 \%$

SAS "Statistical Analysis System"

SUD sangramento uterino disfuncional 


\section{LISTA DE TABELAS}

Tabela 1. Comparação dos resultados histomorfométricos e histológicos das alterações teciduais nos cornos uterinos onde foram injetados ATA (ácido tricloroacético) e SF (soro

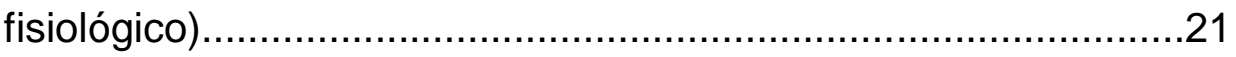

Tabela 2. Comparação dos resultados histomorfométricos e histológicos das alterações teciduais nos cornos uterinos onde foram injetados ATA (ácido tricloroacético) e SF (soro fisiológico) no Grupo 2.....37

Tabela 3. Comparação dos resultados histomorfométricos e histológicos das alterações endometriais nos cornos onde foi injetado ATA entre os Grupos. 51 


\section{LISTA DE GRÁFICOS}

Gráfico 1. Análise das alterações histomorfométricas e histológicas no epitélio superficial do endométrio no Grupo 1, nos cornos onde foram injetados ATA (ácido tricloroacético) e SF (soro fisiológico)

Gráfico 2. Análise das alterações histomorfométricas e histológicas na camada estromal do endométrio no Grupo 1, nos cornos onde foram injetados ATA (ácido tricloroacético) e SF (soro fisiológico)

Gráfico 3. Análise das alterações histomorfométricas e histológicas no número de glândulas por campo de menor aumento no Grupo 1, nos cornos onde foram injetados ATA (ácido tricloroacético) e SF (soro fisiológico) 28

Gráfico 4. Análise das alterações histomorfométricas e histológicas na espessura miometrial no Grupo 1, nos cornos onde foram injetados ATA (ácido tricloroacético) e SF (soro fisiológico) 31

Gráfico 5. Análise das alterações histomorfométricas na camada epitelial do endométrio no Grupo 2, nos cornos onde foram injetados ATA (ácido tricloroacético) e SF (soro fisiológico). .38

Gráfico 6. Análise das alterações histomorfométricas na camada estromal do endométrio no Grupo 2, nos cornos onde foram injetados ATA (ácido tricloroacético) e SF (soro fisiológico). 
Gráfico 7. Análise das alterações histomorfométricas no número de glândulas por campo de menor aumento no Grupo 2, nos cornos onde foram injetados ATA (ácido tricloroacético) e SF (soro fisiológico).

Gráfico 8. Análise das alterações histomorfométricas na espessura miometrial no Grupo 2, nos cornos onde foram injetados ATA (ácido tricloroacético) e SF (soro fisiológico).

Gráfico 9. Análise das alterações histomorfométricas na camada epitelial do endométrio entre os Grupos, nos cornos onde foi injetado ATA (ácido tricloroacético) .52

Gráfico 10. Análise das alterações histomorfométricas na camada estromal do endométrio entre os Grupos, nos cornos onde foi injetado ATA (ácido tricloroacético) .53

Gráfico 11. Análise das alterações histomorfométricas no número de glândulas por campo de menor aumento entre os Grupos, nos cornos onde foi injetado ATA (ácido tricloroacético) .54 


\section{LISTA DE FIGURAS}

Figura 1. Identificação dos cornos uterinos com clampeamento proximal e distal.

Figura 2. Injeção de ATA (ácido tricloroacético) no corno uterino esquerdo.

Figura 3. Aspecto dos cornos uterinos após retirada das pinças cirúrgicas cinco minutos após a injeção do ATA (ácido tricloroacético) e soro fisiológico.

Figura 4. Avaliação histomorfométrica do corno uterino após injeção de SF (soro fisiológico) (HE 200x).

Figura 5. Avaliação histomorfométrica do corno uterino após injeção de ATA (ácido tricloroacético) (HE 200x).

Figura 6. Avaliação histomorfométrica do corno uterino após injeção de SF (soro fisiológico) (HE 40x). 26

Figura 7. Avaliação histomorfométrica do corno uterino após injeção de ATA (ácido tricloroacético) (HE 40x).

Figura 8. Avaliação histomorfométrica do corno uterino após injeção de SF (soro fisiológico) (HE 40x).

Figura 9. Avaliação histomorfométrica do corno uterino após injeção de ATA (ácido tricloroacético) (HE 40x).

Figura 10. Avaliação histomorfométrica do corno uterino após injeção de SF (soro fisiológico) (HE 40x). 
Figura 11. Avaliação histomorfométrica do corno uterino após injeção de ATA (ácido tricloroacético) (HE 40x).

Figura 12. Complicação de longo prazo no Grupo 2.

Figura 13. Identificação de perfuração intestinal e infecção intraabdominal em um dos ratos que morreram durante 0 seguimento do Grupo 2.

Figura 14. Intensa destruição tecidual encontrada em animal do Grupo 2. 36

Figura 15. Avaliação histomorfométrica do corno uterino após injeção de ATA (ácido tricloroacético) (HE 200x).

Figura 16. Avaliação histomorfométrica do corno uterino após injeção de SF (soro fisiológico) (HE 40x).

Figura 17. Avaliação histomorfométrica do corno uterino após injeção de ATA (ácido tricloroacético) (HE 40x).

Figura 18. Avaliação histomorfométrica do corno uterino após injeção de SF (soro fisiológico) (HE 40x).

Figura 19. Avaliação histomorfométrica do corno uterino após injeção de ATA (ácido tricloroacético) (HE 40x).

Figura 20. Avaliação histomorfométrica do corno uterino após injeção de ATA (ácido tricloroacético) (HE 200x).

Figura 21. Avaliação histomorfométrica do corno uterino após injeção de SF (soro fisiológico) (HE 40x). 
Figura 22. Avaliação histomorfométrica do corno uterino após injeção de ATA (ácido tricloroacético) (HE 40x). 49 


\section{RESUMO}

Cocuzza MA. Ablação endometrial com ácido tricloroacético em ratas: estudo histomorfométrico e histológico [Dissertação]. São Paulo. Faculdade de Medicina, Universidade de São Paulo, 2011.

INTRODUÇÃO: O Sangramento Uterino Disfuncional (SUD) é uma das causas mais prevalentes de sangramento uterino, estando relacionado a variações hormonais, independente de causas orgânicas. A ablação endometrial é uma das opções terapêuticas, porém está associada à necessidade de treinamento específico e apresenta alto custo. Este estudo tem como objetivo desenvolver modelo de ablação endometrial em ratas adultas. Além disso, avaliar os efeitos histológicos e histomorfométricos causados pelo ácido tricloroacético no útero desses animais, bem como a regeneração endometrial e o retorno do ciclo estral. MÉTODOS: 30 ratas fêmeas adultas foram divididas em dois grupos. Todos os animais foram submetidos à injeção intra-uterina de SF 0,9\% em um corno uterino e de ácido tricloroacético (ATA) no corno contralateral. O primeiro grupo, constituído de 15 ratas, foi sacrificado após 1 dia da injeção e tiveram os úteros removidos (Grupo 1). O segundo grupo, constituído de 15 ratas, foi sacrificado após voltar a apresentar um ciclo estral normal, quando foram submetidos à coleta de esfregaços vaginais e eutanasiados em fase de diestro, o que ocorreu cerca de 20 a 30 dias após o procedimento (Grupo 2). As espessuras do epitélio superficial e do estroma endometrial, o número de 
glândulas endometriais por campo e a espessura miometrial foram comparadas entre os cornos uterinos de cada animal do Grupo 1. As mesmas comparações foram realizadas entre os cornos dos animais do Grupo 2. Por fim, foi avaliada a regeneração endometrial nos Grupos 1 e 2. RESULTADOS: Todos os animais apresentaram recuperação satisfatória do procedimento, não havendo sinais de toxicidade aguda associada ao uso de ATA. No grupo 1, as medianas da espessura do epitélio superficial do endométrio (ATA 0mm vs. Controle $0,05 \mathrm{~mm}, \mathrm{p}=0,0001$ ), da espessura do estroma endometrial (ATA $0,325 \mathrm{~mm}$ vs. Controle $0,525 \mathrm{~mm}, \mathrm{p}=0,0006$ ), do número de glândulas (ATA 4,5 vs. Controle 6,5, p=0,0012) e da espessura miometrial (ATA $0,25 \mathrm{~mm}$ vs. Controle $0,35 \mathrm{~mm}, \mathrm{p}=0,009$ ) foram significativamente inferior no corno que recebeu a injeção de ATA. No Grupo 2, quatro animais (27\%) morreram na segunda semana após o procedimento e, em seis animais (40\%), o material obtido não pode ser avaliado devido à intensa destruição tecidual. Nos cinco animais restantes (33\%) a mediana da espessura do epitélio superficial do endométrio (ATA 0,0mm vs. Controle $0,05 \mathrm{~mm}, p<0,004$ ), da espessura do estroma endometrial (ATA 0,325mm vs. Controle $0,725 \mathrm{~mm}, p=0,011$ ), do número de glândulas (ATA 3 vs. Controle $6,5, p=0,011$ ) e da espessura miometrial (ATA 0,35mm vs. Controle $0,5 \mathrm{~mm}$, $p=0,024)$, foram significativamente inferior no corno submetido à injeção de ATA. Quanto à mediana da espessura do epitélio superficial do endométrio (Grupo $10 \mathrm{~mm}$ vs. Grupo $20 \mathrm{~mm}, p=1$ ) e à mediana da espessura do estroma endometrial (Grupo 1 0,325mm vs. Grupo 2 0,325mm, $p=0,857$ ), não houve diferenças significantes entre os cornos uterinos submetidos à 
injeção de ATA. A mediana do número de glândulas após a injeção de ATA foi superior no Grupo 1 em comparação ao Grupo $2 \quad(p=0,003)$. CONCLUSÃO: O estudo permitiu o desenvolvimento de um modelo experimental viável de ablação de endométrio em ratas adultas. As alterações histológicas e histomorfométricas encontradas nos cornos uterinos mostraram que o ácido tricloroacético é um potente agente na destruição química endometrial. Não houve regeneração endometrial após retorno ao ciclo estral.

Descritores: Técnicas de ablação endometrial; ácido tricloroacético; Hemorragia uterina disfuncional; abrasão química; endométrio; ratos; feminino 


\section{SUMMARY}

Cocuzza MA. Endometrial ablation using trichloroacetic acid in rat model: histomorphometric and histologic evaluation [Dissertação]. São Paulo. Faculdade de Medicina, Universidade de São Paulo; 2011.

INTRODUCTION: Dysfunctional uterine bleeding is one of the most prevalent causes of uterine bleeding and it is related to hormonal variations without organic causes. Endometrial ablation is a therapeutic option but the methods are frequently expensive and dependent of high cost technologies. The objective of the present study is to develop an animal model of endometrial ablation in adults' female rats. In addition, to evaluated the histological and histomorphometric effects after trichloroacetic acid (TCA) exposure into uterine cavity. METHODS: A total of thirty female adult rats were divided in two groups of 15 rats each. All animals were submitted to injection of $0,3 \mathrm{ml}$ of TCA $90 \%$ in one uterine horn and the same amount of saline solution $0,9 \%$ (control) in the other. Group 1 was sacrificed in the following day of the procedure, whereas group 2 was sacrificed in phase of diestrous after recovery of normal estral cycle identified by vaginal smears, approximately 20 to 30 days after the procedure. Superficial epithelia of the endometrium, estromal thickness, number of endometrial glands as well as of myometrium thickness were assessed and compared between the uterine horns of the same rats of group 1. The same evaluation was performed in group 2. Also, endometrial regeneration was evaluated comparing histological alterations in 
the uterine horn that was injected with TCA in group 1 and 2. RESULTS: All animals recovered satisfactorily from the procedure. In group 1, superficial epithelia of the endometrium (TCA $0,0 \mathrm{~mm}$ vs $0,05 \mathrm{~mm}$ control, $p=0,0001$ ), estromal thickness (TCA $0,325 \mathrm{~mm}$ vs $0,525 \mathrm{~mm}$ Control, $p=0,009$ ), number of endometrial glands (TCA $4,5 \mathrm{~mm}$ vs $6,5 \mathrm{~mm}$ control, $p=0,001$ ) and mean myometrial thickness (TCA $0,25 \mathrm{~mm}$ vs $0,35 \mathrm{~mm}$ Control, $p=0,0006$ ) presented a significant difference between the horns showing endometrial destruction on TCA uterine horn. In group 2, four rats $(27 \%)$ died in the second week after the initial procedure and six rats (40\%) had no viable material to be analyzed due to extent tissue destruction. The rest of the group (33\%) showed a mean superficial epithelia of the endometrium (TCA $0,0 \mathrm{~mm}$ vs $0.05 \mathrm{~mm}$ control, $p<0,004$ ), mean estromal thickness (TCA $0,325 \mathrm{~mm}$ vs $0,725 \mathrm{~mm}$ Control, $p=0,011)$, mean number of endometrial glands (TCA 3 vs 6,5 control, $p=0,011$ ) and mean myometrial thickness (TCA $0,35 \mathrm{~mm}$ vs $0.5 \mathrm{~mm}$ Control, $p=0,024)$ significant different between horns showing endometrial destruction on TCA uterine horn. There was no significant difference in the mean superficial epithelia of the endometrium (group $10 \mathrm{~mm}$ vs. group $20 \mathrm{~mm}, p=1$ ) and mean estromal thickness (group 1 $0,325 \mathrm{~mm}$ vs. group $20,325 \mathrm{~mm}, p=0,857$ ) between TCA uterine horn from both groups. However, number of endometrial glands $(4,5 \mathrm{~mm}$ in group 1 vs 3 $\mathrm{mm}$ in group 2, $p=0,003)$ was higher in group 1. CONCLUSION: The study developed a valid model for endometrial ablation in adult female's rats. The histological and histomorphometric effects observed in the uterine horns showed that the trichloroacetic acid is a potent agent for endometrial ablation 
in rat model. In the current model no endometrial regeneration was observed after recovery of normal estral cycle.

Keywords: endometrial ablation techniques; trichloroacetic acid; tissue destruction; dysfunctional uterine hemorrhage; endometrium; chemexfoliation; endometrium; rats; female 
1. INTRODUÇÃO 


\section{INTRODUÇÃO}

O Sangramento Uterino Disfuncional (SUD) é uma afecção ginecológica comum que interfere na qualidade de vida de mulheres em idade reprodutiva, principalmente acima dos 35 anos durante o período prémenopausal. Caracteriza-se por perda sanguínea igual ou maior que $80 \mathrm{ml}$ por ciclo menstrual, não relacionada a gestação, doença pélvica ou sistêmica ${ }^{1}$.

No Reino Unido, o SUD acomete aproximadamente $22 \%$ das mulheres saudáveis no período pré-menopausal, sendo a principal causa de anemia por deficiência de ferro em países desenvolvidos ${ }^{2,3}$.

O sangramento menstrual normal decorre de ciclos ovulatórios, devido à ação do estrogênio e progesterona no endométrio. $O$ endométrio é derivado da camada mucosa dos ductos Mullerianos fundidos e devendo estar completamente diferenciado até vigésima semana de gestação. Caracteriza-se como um dos tecidos mais complexos do corpo humano, respondendo a variações cíclicas hormonais ${ }^{4}$.

Durante o ciclo menstrual, o componente glandular, estromal e vascular do endométrio apresentam alterações anatômicas e funcionais caracterizadas por crescimento e regressão. Esses eventos se repetem aproximadamente 400 vezes durante a vida da mulher adulta ${ }^{5}$.

O endométrio pode ser dividido morfologicamente em camada funcional e basal, caracterizado pelos dois terços superficiais e terço profundo, respectivamente. Na camada funcional ocorrem alterações de 
proliferação, secreção e degeneração. A função da camada basal é produzir o endométrio regenerativo após a descamação menstrual da camada funcional.

O ciclo endometrial pode ser dividido em quatro fases: 1) fase proliferativa, 2) fase secretória, 3) fase secretória tardia ou implantacional, 4) fase menstrual. Durante a primeira fase há reconstrução e crescimento do endométrio. Além disso, ocorre a formação da camada epitelial contínua revestindo a cavidade endometrial, crescimento e edema do estroma, e crescimento glandular. A espessura endometrial aumenta de $0,5 \mathrm{~mm}$ para 3,5 a 5,0 mm, com pico entre o oitavo e décimo dia do ciclo menstrual. A fase secretória, após a ovulação, é caracterizada por aumento da complexidade do tecido, e principalmente pela tortuosidade das glândulas. A espessura endometrial não aumenta nesse período, provavelmente devido à ação da progesterona ${ }^{6}$. Alterações significativas ocorreram até a fase de implantação, período marcado por um importante edema do estroma, contendo glândulas tortuosas e dilatadas, vasos extremamente espiralados, compondo aproximadamente $50 \%$ da espessura total do endométrio. Quando a fertilização não ocorre, a queda da produção de estrogênio e progesterona desencadeia três eventos: alterações vasomotoras, perda tecidual e menstruação. A queda desses hormônios desestabiliza a membrana dos lisossomos, liberando enzimas para síntese de prostaglandinas, proteases e colagenases. Vasoconstricção prolongada e altos níveis de prostaglandinas caracterizam essa fase de descamação endometrial. 
O SUD decorre principalmente de altos níveis de estrogênio mantidos, desencadeando um crescimento anormal do endométrio, sem suporte estrutural. O estroma, devido à falta de progesterona, é frágil e susceptível a descamações desordenadas e assincrônicas. Os mecanismos envolvidos nessa desordem continuam em investigação, mas parecem estar relacionados a níveis anormais de enzimas fibrinolíticas e prostaglandinas vasodilatadoras no endométrio ${ }^{7}$.

Mulheres com fluxo menstrual excessivo apresentam produção anormal de prostaglandinas, sendo os anti-inflamatórios inibidores da síntese de prostaglandinas uma possibilidade de tratamento.

A primeira linha de tratamento geralmente é medicamentosa e inclui inúmeras modalidades terapêuticas como; anti-inflamatórios não hormonais, contraceptivos orais, progestagênios, agonistas do GNRH, danazol ou dispositivo intra uterino de levonorgestrel. Apesar disso, essas opções estão associadas a taxas variáveis de insucesso relacionadas tanto à intolerância ao uso da medicação como à recorrência após a interrupção do tratamento ${ }^{8}$. Após a recorrência, na maioria das vezes, é necessária a utilização dos tratamentos invasivos. A histerectomia, ou retirada do útero, é a opção cirúrgica mais efetiva no tratamento do SUD ${ }^{9}$. Anualmente, nos Estados Unidos são realizadas aproximadamente 600.000 histerectomias, sendo $50 \%$ indicadas por SUD ${ }^{10,11}$. Apesar de resolver o sangramento endometrial em todos os casos, a histerectomia é um procedimento invasivo com incidência não desprezível de complicações como hemorragias e infecções, independente da via de acesso utilizada ${ }^{12,13}$. Sendo assim, como o SUD é 
uma condição benigna, a opção de tratamento através de procedimentos menos agressivos, evitando-se a retirado do útero, tornou-se um importante atrativo ${ }^{14}$. Muitas técnicas foram introduzidas nos últimos 20 anos, baseando-se fundamentalmente na destruição do endométrio, ou ablação endometrial. Nesses procedimentos deve ser destruída a camada basal do endométrio, responsável pela regeneração tecidual.

Em 1981 foi realizada a primeira ablação endometrial através da histeroscopia, a qual permitiu visualização direta da cavidade uterina. As técnicas que são realizadas com a utilização de um histeroscópio são também denominadas técnicas de "primeira geração", e utilizam eletrocirurgia ou laser para ablação endometrial ${ }^{15}$. Apesar de esse procedimento necessitar de internação com curta duração, deve ser realizado sob anestesia geral ou regional e requer treinamento cirúrgico especifico. Após ablação histeroscópica realizada por cirurgião experiente, $16 \%$ dos casos evolui com recorrência de sangramento ${ }^{16}$. Essas taxas de insucesso da ablação endometrial podem atingir até $38 \%$ dos casos quando o procedimento inicial é realizado em centros acadêmicos ou cirurgiões com pouca experiência ${ }^{17}$.

Apesar dos procedimentos histeroscópicos cursarem com menos complicações que a histerectomia, em $4 \%$ dos casos pode ocorrer perfuração uterina, hemorragia, infecção ou sobrecarga de volume associada à hiponatremia ${ }^{18}$. As técnicas não histeroscópicas, denominadas de "segunda geração", compreendem a destruição endometrial sem a visualização direta da cavidade uterina através da aplicação de calor, frio ou 
radiofreqüência ${ }^{19}$. Essas técnicas, no entanto, podem ser realizadas sem necessidade de internação hospitalar, com anestesia local e requerem menor treinamento cirúrgico prévio quando comparadas às técnicas de primeira geração. Esses procedimentos apresentam menor tempo cirúrgico e menos complicações quando comparados as técnicas histeroscópicas. No entanto, são necessários equipamentos específicos que elevam o custo dos procedimentos $^{20}$.

As técnicas de ablação endometrial (primeira e segunda geração) quando comparadas a histerectomia, apresentam menor tempo de hospitalização, baixa morbidade e resultados semelhantes ${ }^{21}$. No entanto, requerem treinamento cirúrgico específico ou custo elevado. Por essa razão, a possibilidade da utilização de um agente químico para ablação endometrial, com baixo custo, aplicação ambulatorial, menor complicação e reduzida curva de aprendizado parece bastante atrativa.

Recentemente, Kucuk et al. relataram mais de $90 \%$ de sucesso com a aplicação tópica de acido tricloroacético intra-uterino em mulheres com diagnóstico de SUD. No entanto, por tratar-se de um estudo clínico, não foi realizada avaliação das alterações histológicas uterinas "in vivo" após o tratamento com ATA ${ }^{2}$.

O ácido tricloroacético é um agente que provoca desnaturação protéica causando uma cauterização química tecidual. Esse ácido é usualmente utilizado no tratamento de papilomas genitais, sem efeitos sistêmicos colaterais ${ }^{22}$. 
A avaliação experimental das alterações histopatológicas ocasionadas pelo ATA ainda não foi devidamente documentada.

O ciclo reprodutivo de roedores é conhecido como ciclo estral e é mediado pelos hormônios ovarianos, estrogênio e progesterona. O ciclo estral dura em média quatro dias e pode ser dividido em quatro fases: proestro, estro, metaestro e diestro. A identificação da fase do ciclo pode ser realizada através da análise do esfregaço vaginal. $O$ proestro é caracterizado pelo crescimento do trato genital e o esfregaço vaginal contém poucos leucócitos, células epiteliais nucleadas e algumas cornificadas. No estro há crescimento do trato genital, inchaço da vulva e no esfregaço vaginal não aparecem leucócitos, mas aparecem células epiteliais nucleadas e predominantemente cornificadas. O metaestro é um período de mudanças degenerativas do trato genital, apresentando o predomínio de leucócitos, células epiteliais cornificadas e nucleadas no esfregaço vaginal. O diestro é um período quiescente de crescimento lento e no esfregaço vaginal aparecem células epiteliais nucleadas, leucócitos e muco espesso e abundante.

A ablação endometrial realizada após preparo endometrial tornando-o mais fino apresenta maior taxa de amenorréia em mulheres com SUD. A menor espessura endometrial no momento do procedimento é o provável motivo do elevado sucesso pela menor capacidade de regeneração do endométrio devido à destruição da camada basal ${ }^{23,24}$. Sendo assim, em nosso projeto, utilizamos animais em fase diestro, buscando uma menor espessura endometrial e otimizando a ação do ATA. 
2. OBJETIVOS 


\section{OBJETIVOS}

- Desenvolver o modelo de ablação endometrial em ratas adultas;

- Avaliar os efeitos histológicos e histomorfométricos causados pelo ácido tricloroacético no endométrio de ratas adultas;

- Avaliar se a instilação de ácido tricloroacético interfere na regeneração endometrial. 
3. MATERIAL E MÉTODOS 


\section{MATERIAL E MÉTODOS}

\subsection{PROJETO PILOTO}

O projeto piloto teve início em Junho de 2008 no Laboratório de Ginecologia Estrutural e Molecular da Disciplina de Ginecologia da Faculdade de Medicina da Universidade de São Paulo - LIM 58, contando com a infra-estrutura necessária para o desenvolvimento do trabalho (Anexo 1).

\subsubsection{CÁLCULO DO VOLUME DE LÍQUIDO INJETADO}

Após a pesagem dos animais, o volume médio de líquido injetado foi calculado em três ratas. Através de incisão mediana de aproximadamente três $\mathrm{cm}$ no abdome, foram acessados os cornos uterinos. Somente um dos cornos foi utilizado para a injeção de soro fisiológico. Após clampeamento da porção distal do corno uterino, foi introduzida uma agulha $(13 \times 4,5)$ em sua porção proximal e injetado volume necessário para o preenchimento total desse corno. Após esse procedimento, os animais foram sacrificados e seus úteros pesados. Os valores obtidos foram inseridos na seguinte equação:

Peso do útero X Peso do Animal X Volume Injetado

Por meio dessa equação obtivemos o volume de $0,3 \mathrm{ml}$ a ser injetado na cavidade cornual de cada animal. 


\subsubsection{DEFINIÇÃO DA CONCENTRAÇÃO DO ATA A SER UTILIZADO}

Utilizamos nove ratas, as quais foram alocadas em três grupos. Os animais desses grupos foram submetidos à injeção das seguintes concentrações de ATA: $50 \%, 70 \%$ e $90 \%$. No dia seguinte ao procedimento, os animais foram sacrificados, os úteros removidos e fixados em formaldeido a $10 \%$. O material foi então embebido em parafina e corado com hematoxilina e eosina, para posterior análise histomorfométrica e histológica. Após o preparo das lâminas, os seguintes parâmetros foram avaliados: espessura do epitélio superficial do endométrio, espessura do estroma endometrial, número de glândulas endometriais por campo e espessura miometrial. Os resultados permitiram estabelecer a concentração de $90 \%$ como a mais efetiva para a ablação endometrial.

\subsection{MATERIAIS}

Um total de 30 ratas da linhagem Wistar, fêmeas, adultas, pesando aproximadamente 250 a 300 gramas, provenientes do Centro de Bioterismo da Faculdade de Medicina da Universidade de São Paulo foram utilizadas no estudo realizado no Laboratório de Ginecologia Estrutural e Molecular do Departamento de Ginecologia da Faculdade de Medicina da universidade de São Paulo - LIM 58, no período de março a de setembro de 2009. Os procedimentos cirúrgicos foram realizados no Centro de Bioterismo da Faculdade de Medicina da Universidade de São Paulo. 
Os animais foram mantidos de acordo com normas já padronizadas, com temperatura, umidade e ciclo de luz adequados para essa espécie. Foram alojados em gaiolas de propileno e fundo plástico com leito de maravalha. Os animais tiveram livre acesso a alimentos e água durante a pesquisa.

\subsection{MÉTODO}

Esse projeto foi aprovado pelo Comitê de Ética para Projetos de Pesquisa - CAPPesq sob o número 0629/07 (Anexo 2). Foram utilizados 30 animais, divididos em dois grupos. Inicialmente foram efetuadas coletas de esfregaços vaginais para identificação da fase de diestro. Todos os animais foram submetidos ao mesmo procedimento cirúrgico. Foram anestesiados com injeção intraperitoneal de Ketamina $100 \mathrm{mg} / \mathrm{Kg}$ e Xylazina $(20 \mathrm{mg} / \mathrm{Kg})$. O material cirúrgico utilizado foi previamente submetido à desinfecção com álcool $70 \%$. Após tricotomia abdominal, uma incisão mediana de três $\mathrm{cm}$ foi realizada, permitindo acesso aos cornos uterinos. Após identificação dos cornos uterinos foi realizado o clampeamento na região distal e proximal dos mesmos, utilizando-se de pinças Kelly, próximo ao oviduto (Figura 1). 
Figura1. Identificação dos cornos uterinos com clampeamento proximal e distal

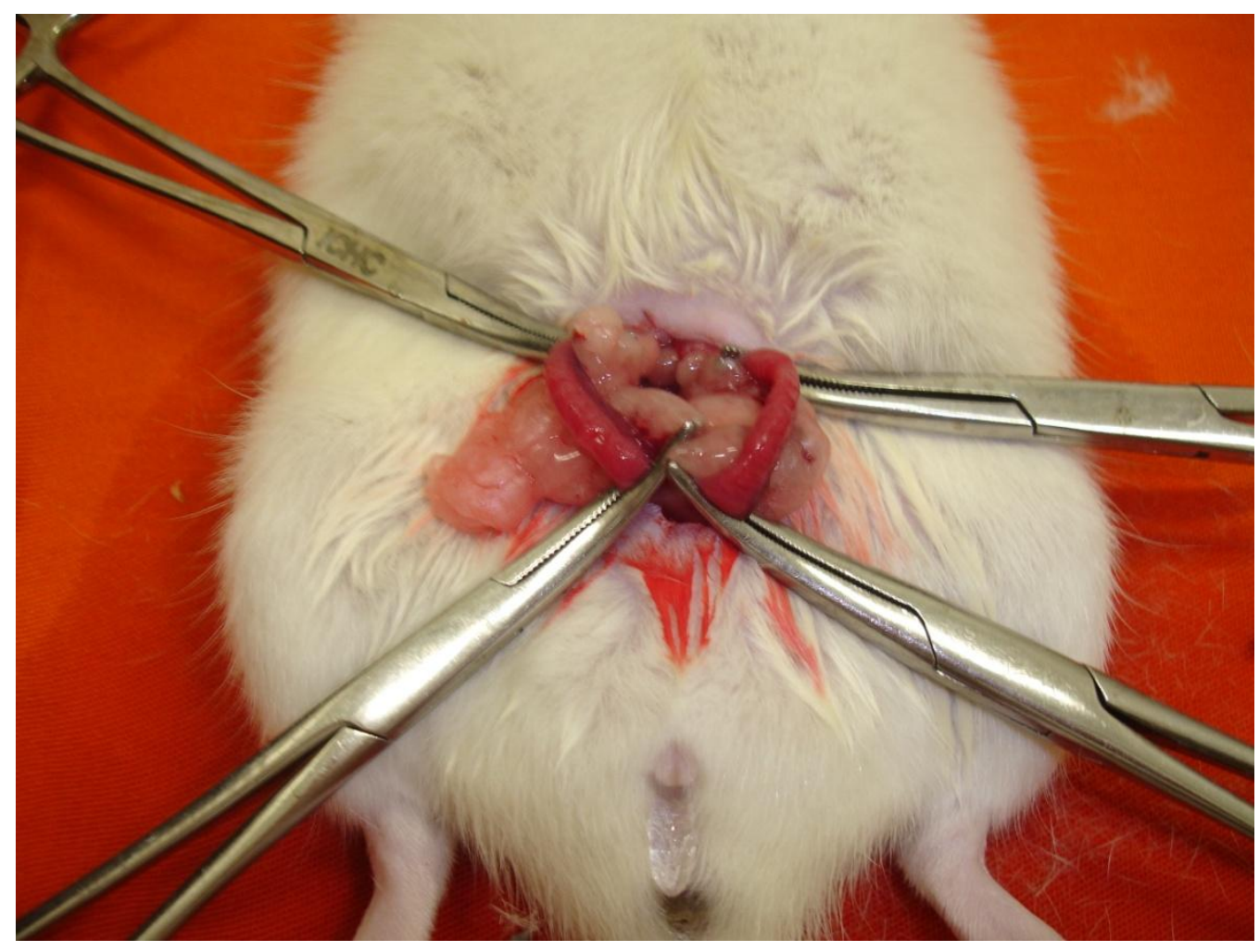


Através de punção com agulha de insulina $(13 \times 4,5)$ foi realizada injeção de 0,3 ml de ATA a 90\% (Figura 2).

Figura 2. Injeção de ATA (ácido tricloroacético) no corno uterino esquerdo

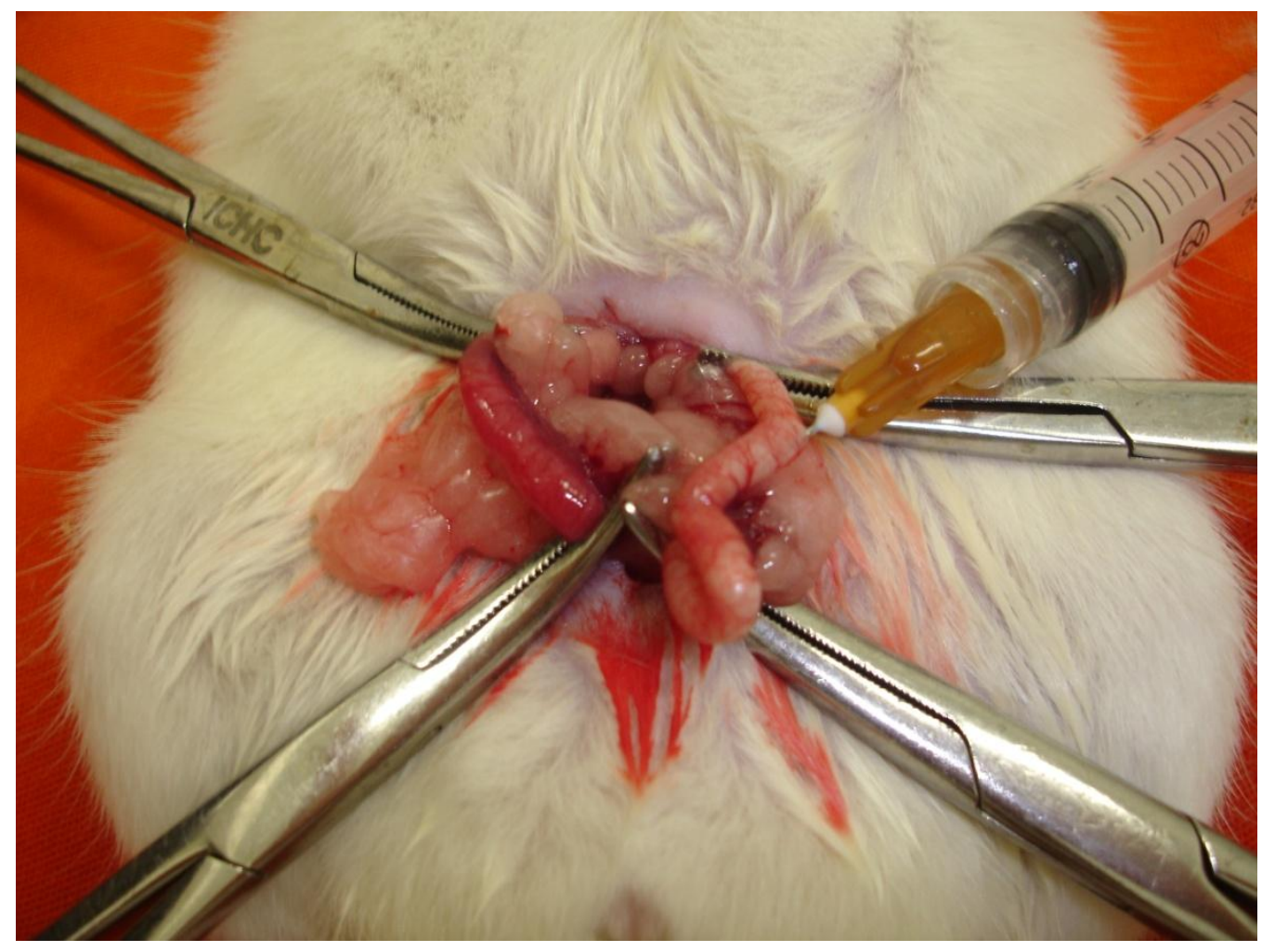

No corno contralateral foi injetado $0,3 \mathrm{ml}$ de soro fisiológico $0,9 \%$. Após 5 minutos, as pinças foram retiradas e o abdome suturado com fio de nylon 3.0 (Figura 3). 
Figura 3. Aspecto dos cornos uterinos após retirada das pinças cirúrgicas cinco minutos após a injeção do ATA (ácido tricloroacético) e soro fisiológico.

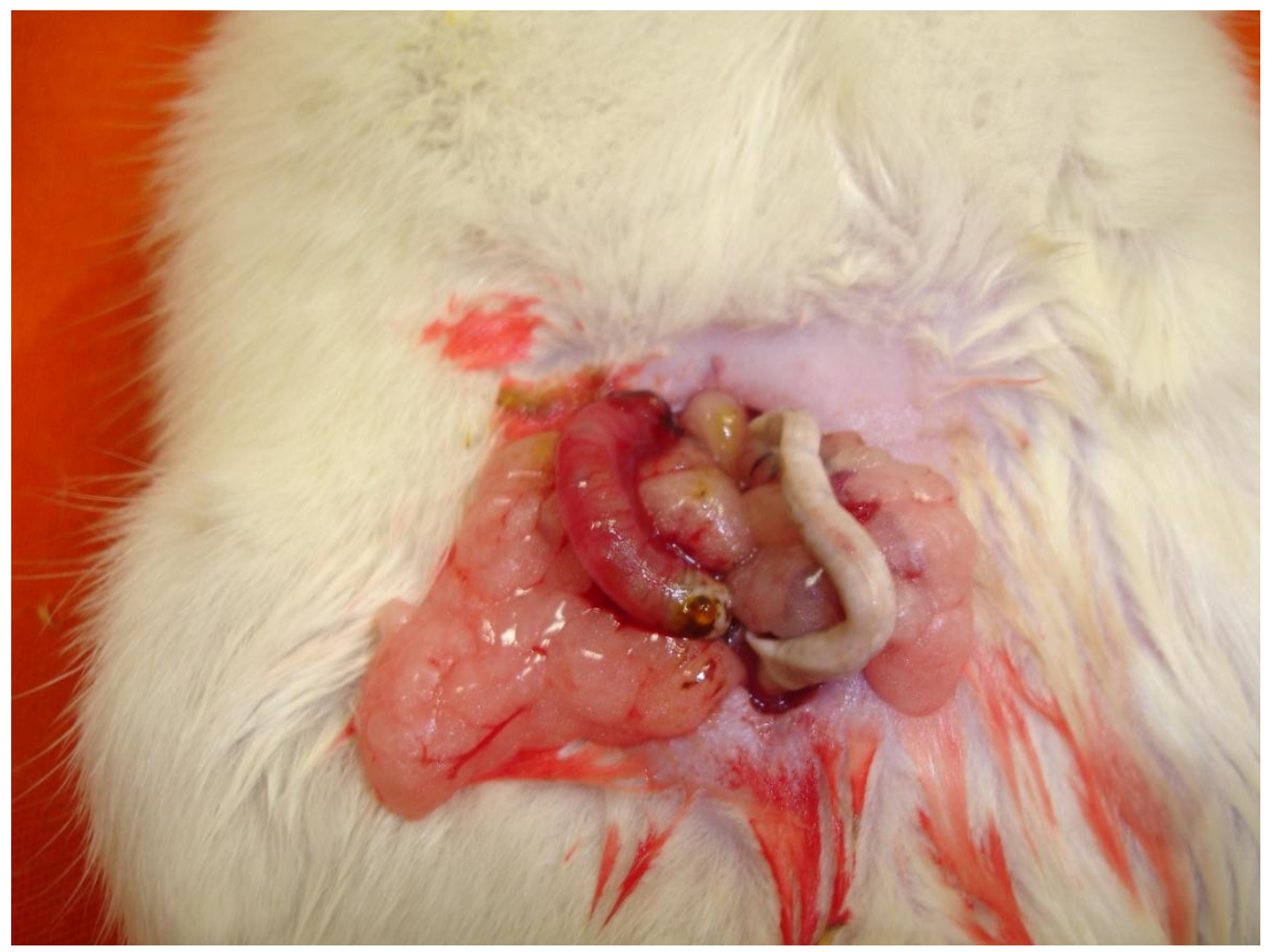

Os animais foram então seguidos conforme descrito no desenho do projeto (Anexo 1).

O primeiro grupo, constituído de 15 ratas, foi sacrificado após 1 dia da injeção, e tiveram os úteros removidos (Grupo 1). Os cornos uterinos foram fixados em formaldeído para posterior avaliação histológica. O segundo grupo foi sacrificado após voltar a apresentar um ciclo estral normal. Os animais foram submetidos à coleta de esfregaços vaginais e sacrificados em 
fase de diestro, o que ocorreu cerca de 20 a 30 dias do procedimento cirúrgico (Grupo 2).

O sacrifício dos animais foi feito através do uso de câmara de gás CO2, onde os animais receberam fluxo de $\mathrm{CO} 2$ a $100 \%$ durante 5 minutos. Após o sacrifício, realizou-se a histerectomia e o material foi fixado em formaldeído a $10 \%$.

\subsubsection{Avaliação Histomorfométrica e Histológica}

Após a retirada do útero, este foi fixado em formaldeido a 10\% para avaliação histológica. Após a fixação, os fragmentos foram desidratados e processados para inclusão em parafina. A inclusão foi realizada de forma a obter cortes transversais dos cornos uterinos com $4 \mu \mathrm{m}$ de espessura. Após cortados os blocos e confeccionadas as lâminas, estas foram coradas com hematoxilina e eosina. Por microscopia óptica foram avaliados a espessura do epitélio superficial do endométrio, a espessura do estroma endometrial, o número de glândulas endometriais por campo e a espessura miometrial. A análise morfométrica foi realizada manualmente em microscópio utilizando retículo de diâmetro $21 \mathrm{~mm}$, escala de 0 a $10 \mathrm{~mm}$ e resolução de $0,05 \mathrm{~mm}$, por dois pesquisadores.

As alterações histológicas e histomorfométricos foram comparadas entre os cornos do Grupo 1. As mesmas comparações foram realizadas entre os cornos do Grupo 2. Por fim, foi avaliada a capacidade de regeneração endometrial pela comparação entre as alterações na espessura 
do epitélio superficial do endométrio, a espessura do estroma endometrial e o número de glândulas endometriais por campo entre os cornos submetidos à injeção de ATA nos Grupos 1 e 2.

\subsubsection{Análise Estatística}

A análise estatística foi realizada utilizando o programa JMP (JMP®) 7.0.1, SAS Institute Inc. 2007, NC - EUA). Para variáveis contínuas e com distribuição normal utilizou-se o teste t de Student. Para variáveis contínuas, com distribuição não-normal, utilizou-se o teste Wilcoxon Rank Sum. Todos os testes foram bicaudais e considerados significantes quando $p<0,05$. 
4. RESULTADOS 


\section{RESULTADOS}

\subsection{Grupo 1}

Todos os animais do primeiro grupo foram submetidos ao procedimento conforme descrito no Anexo 1 , não havendo sinais de toxicidade associada ao uso do ATA. Os animais apresentaram recuperação anestésica sem intercorrências, alimentando-se normalmente no pósoperatório imediato.

Os resultados relativos a esse grupo foram analisados considerandose as variáveis assinaladas na Tabela 1. 
Tabela 1. Comparação dos resultados histomorfométricos e histológicos das alterações teciduais nos cornos uterinos onde foram injetados ATA (ácido tricloroacético) e SF (soro fisiológico) no Grupo 1

\begin{tabular}{|c|c|c|c|}
\hline & ATA & SF & $p$ value \\
\hline \multicolumn{4}{|l|}{ Espessura do epitélio } \\
\hline $\begin{array}{l}\text { superficial do endométrio } \\
(\mathrm{mm})\end{array}$ & $0(0-0)$ & $0,05(0,05-0,05)$ & $<0,001^{*}$ \\
\hline $\begin{array}{l}\text { Espessura do estroma } \\
\text { endometrial (mm) }\end{array}$ & $0,325(0,3-0,35)$ & $0,525(0,4-0,775)$ & $0,006^{*}$ \\
\hline $\begin{array}{l}\text { Número de glândulas por } \\
\text { campo }\end{array}$ & $4,5(4-6)$ & $6,5(5,5-7,5)$ & $0,001^{*}$ \\
\hline $\begin{array}{l}\text { Espessura miometrial } \\
(\mathrm{mm})\end{array}$ & $0,25(0,225-0,3)$ & $0,35(0,3-0,425)$ & $0,009^{*}$ \\
\hline
\end{tabular}

\subsubsection{Espessura do epitélio superficial do endométrio}

A mediana da espessura do epitélio superficial do endométrio após a injeção de ATA e SF foi de $0 \mathrm{~mm} \quad(0-0)$ e $0,05 \mathrm{~mm} \quad(0,05-0,05)$, respectivamente (Gráfico 1). 
Gráfico 1. Análise das alterações histomorfométricas na camada superficial do endométrio no Grupo 1, nos cornos onde foram injetados ATA (ácido tricloroacético) e SF (soro fisiológico)

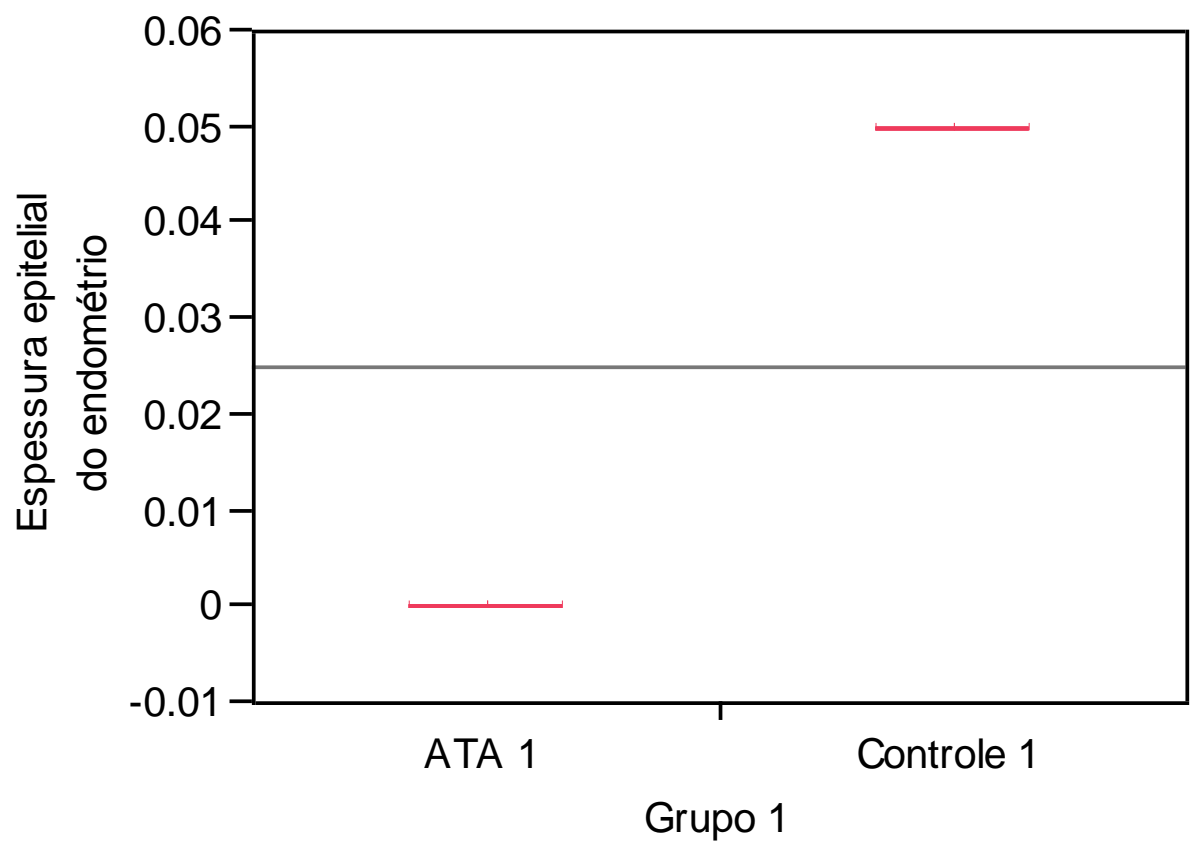

Houve diferença significante entre a espessura do epitélio superficial do endométrio nos cornos uterinos onde foram injetados ATA e SF $(p=0,0001)$ (Figuras 4 e 5$)$. 
Figura 4. Avaliação histomorfométrica do corno uterino após injeção de SF (soro fisiológico), sem alterações no epitélio superficial do endométrio. (HE 200x)

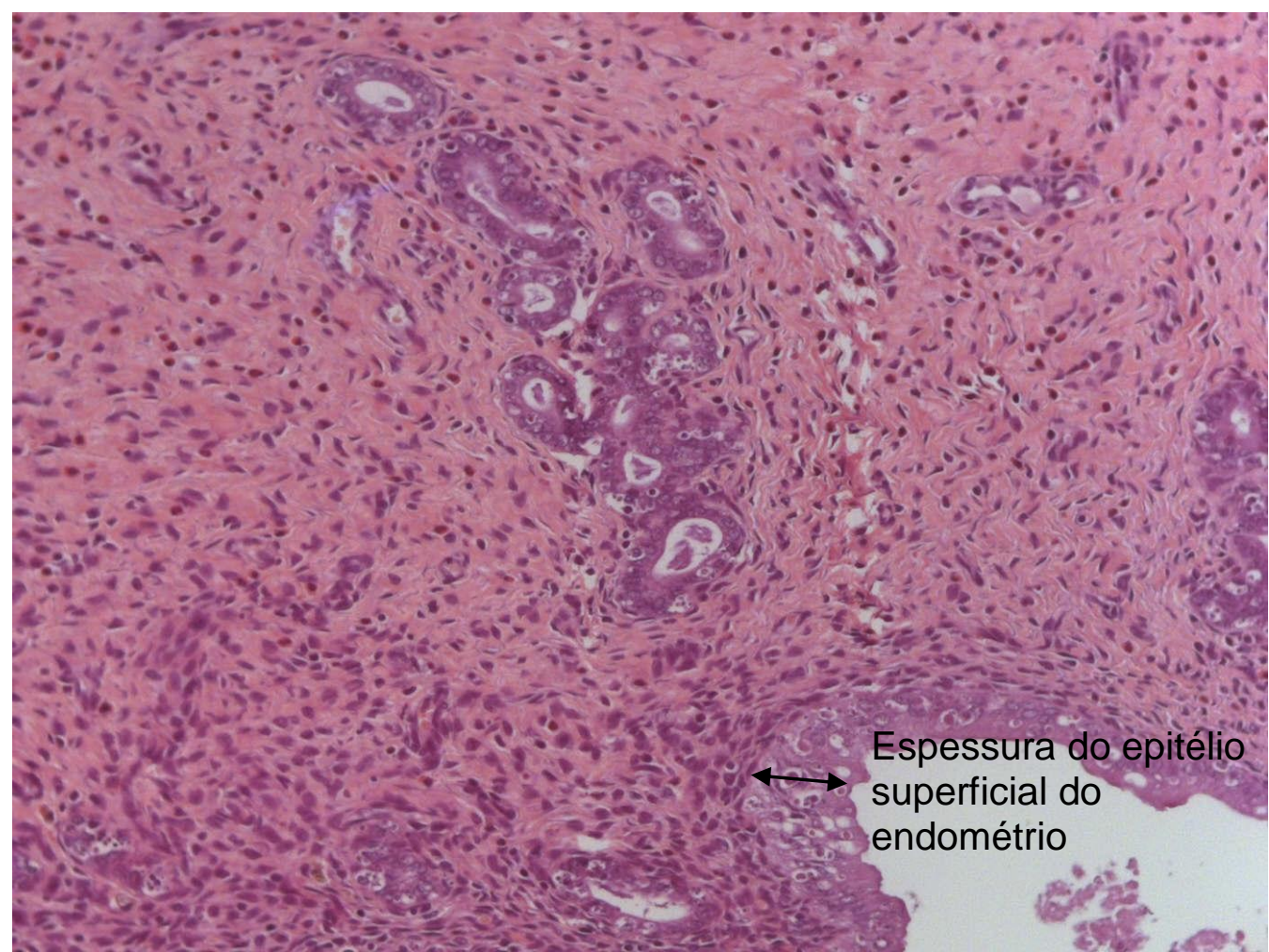


Figura 5. Avaliação histomorfométrica do corno uterino após injeção de ATA (ácido tricloroacético), demonstrando destruição completa do epitélio superficial do endométrio. (HE 200x)

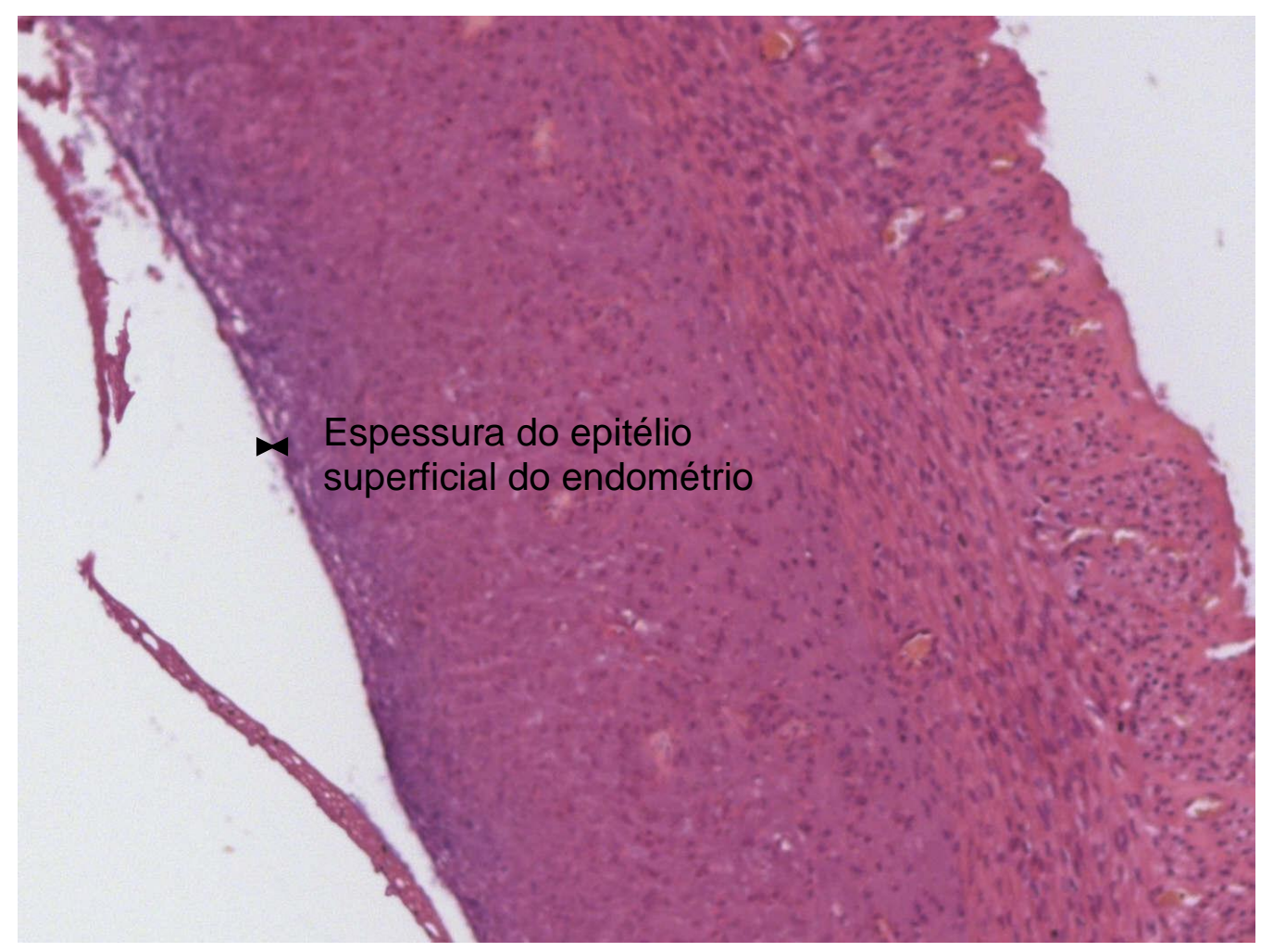

\subsubsection{Espessura do estroma endometrial}

A mediana da espessura do estroma endometrial após a injeção de ATA e SF foi de $0,325 \mathrm{~mm} \quad(0,3-0,35)$ e $0,525 \mathrm{~mm} \quad(0,4-0,775)$, respectivamente (Gráfico 2). 
Gráfico 2. Análise das alterações histomorfométricas na camada estromal do endométrio no Grupo 1, nos cornos onde foram injetados ATA (ácido tricloroacético) e SF (soro fisiológico)

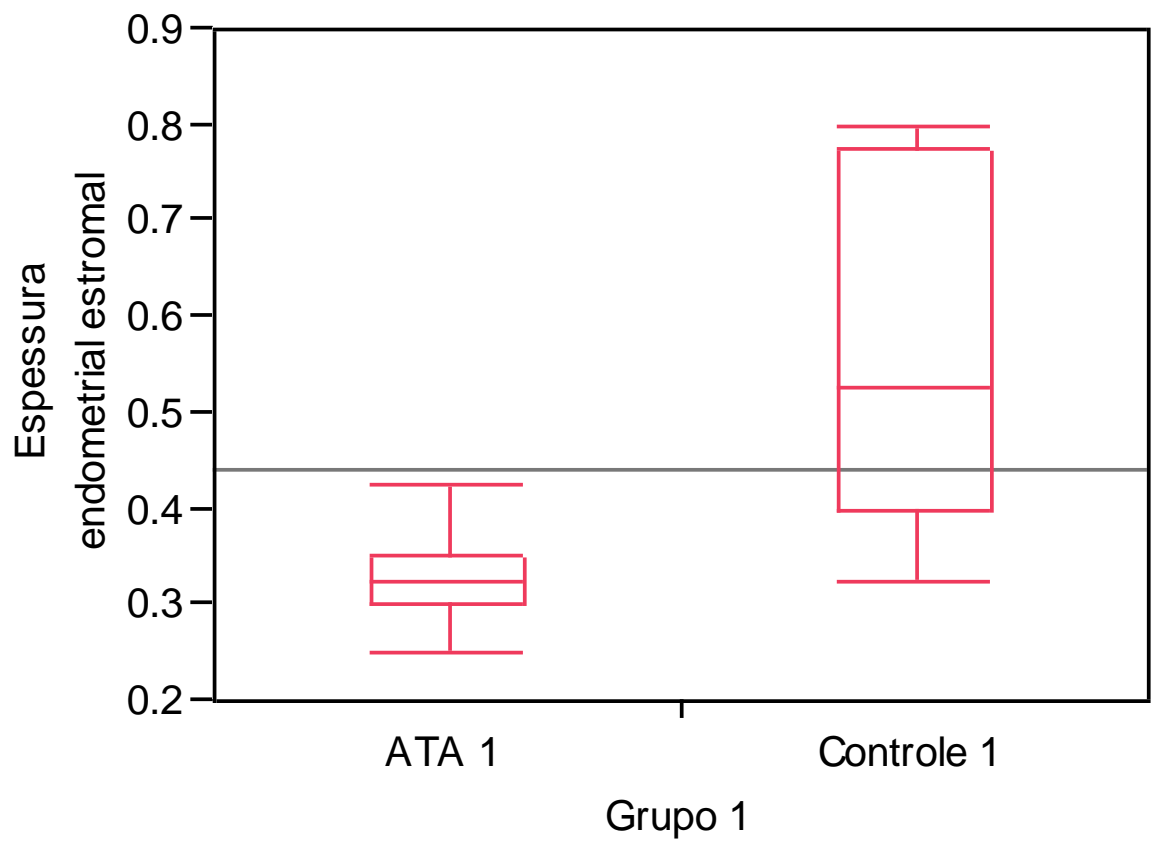

Houve diferença significante entre a espessura do estroma endometrial nos cornos uterinos onde foram injetados ATA e SF $(p=0,0006)$ (Figuras 6 e 7). 
Figura 6. Avaliação histomorfométrica do corno uterino após injeção de SF (soro fisiológico), demonstrando ausência de alterações na camada estromal do endométrio. (HE 40x)

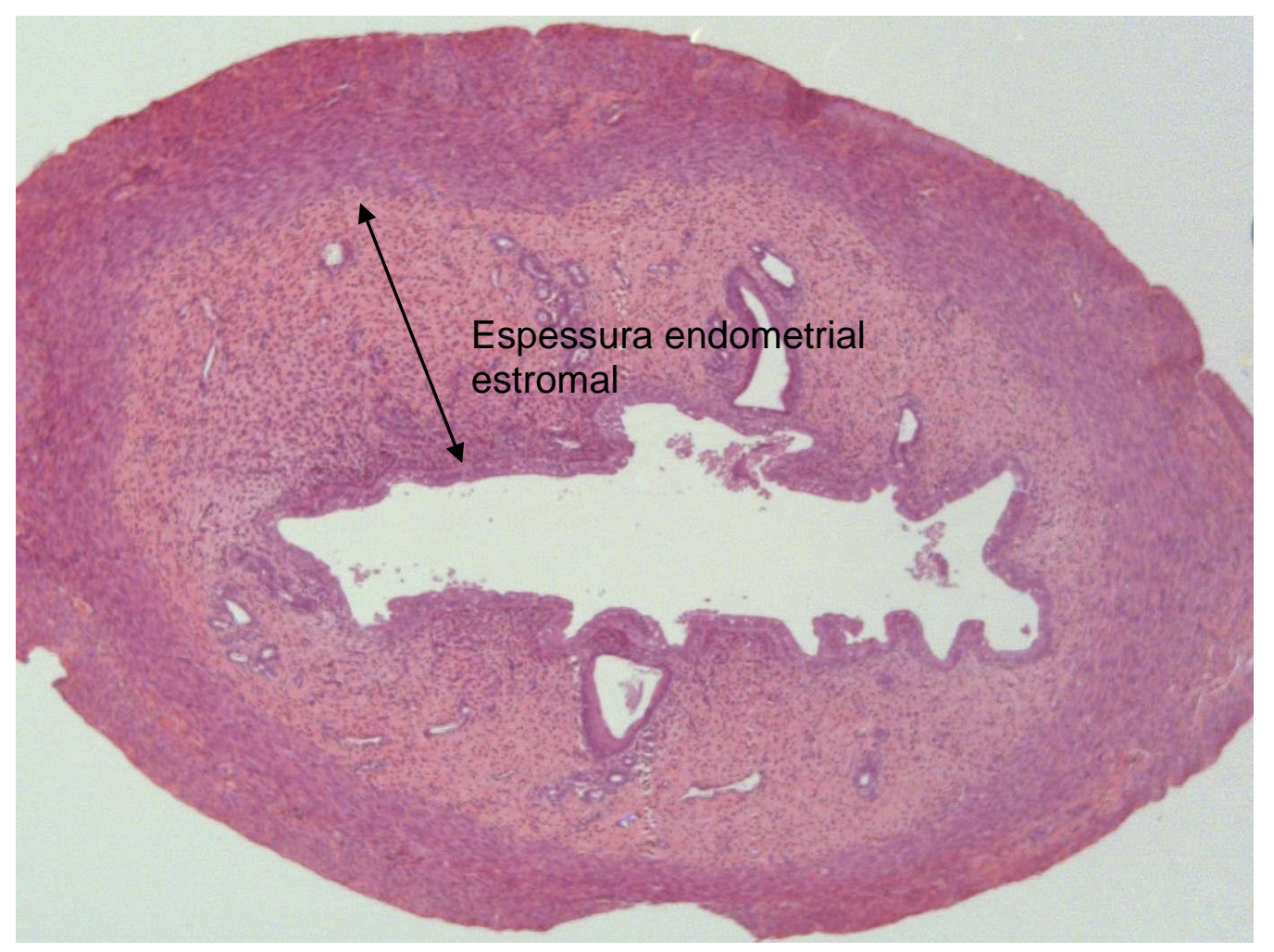


Figura 7. Avaliação histomorfométrica do corno uterino após injeção de ATA (ácido tricloroacético), demonstrando alterações significativas da espessura da camada estromal do endométrio. (HE 40x)

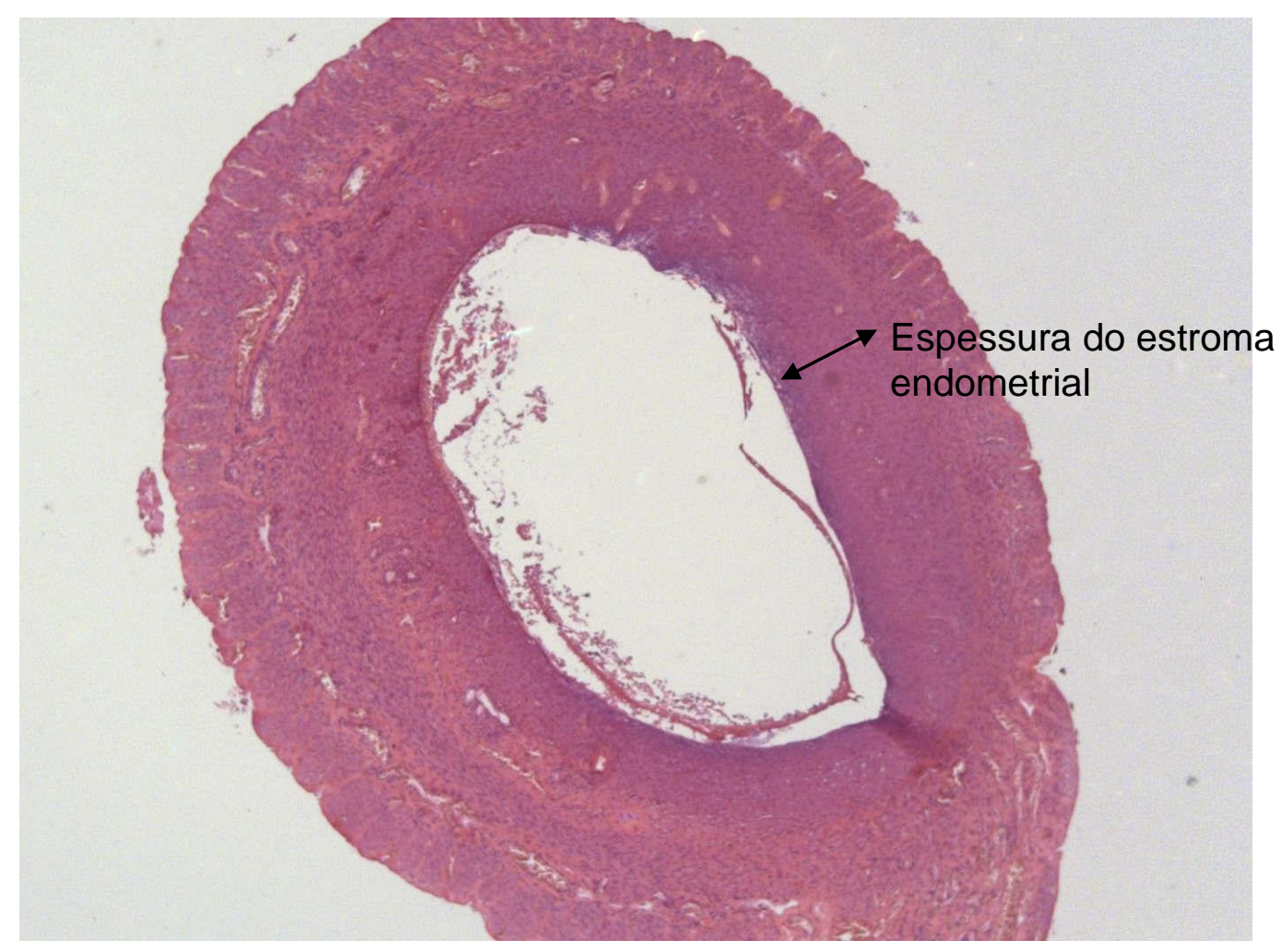

\subsubsection{Número de glândulas por campo}

A mediana do número de glândulas por campo de menor aumento após a injeção de ATA e SF foi de 4,5 (4-6) e 6,5 (5,5-7,5), respectivamente (Gráfico 3). 
Gráfico 3. Análise das alterações histomorfométricas no número de glândulas por campo de menor aumento no Grupo 1, nos cornos onde foram injetados ATA (ácido tricloroacético) e SF (soro fisiológico)

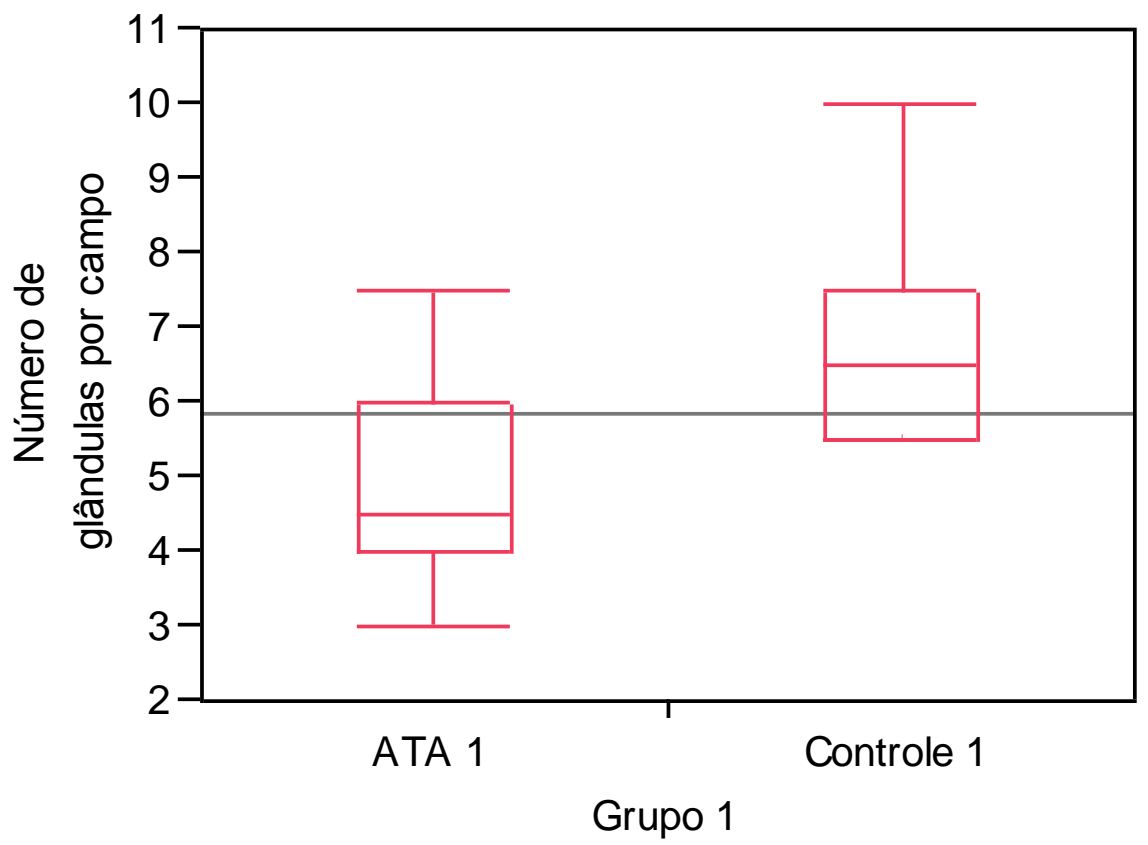

Houve diferença significante entre o número de glândulas por campo nos cornos uterinos onde foram injetados ATA e SF $(p=0,0012)$ (Figuras 8 e 9). 
Figura 8. Avaliação histomorfométrica do corno uterino após injeção de SF (soro fisiológico), demonstrando ausência de alterações no número de glândulas. (HE 40x)

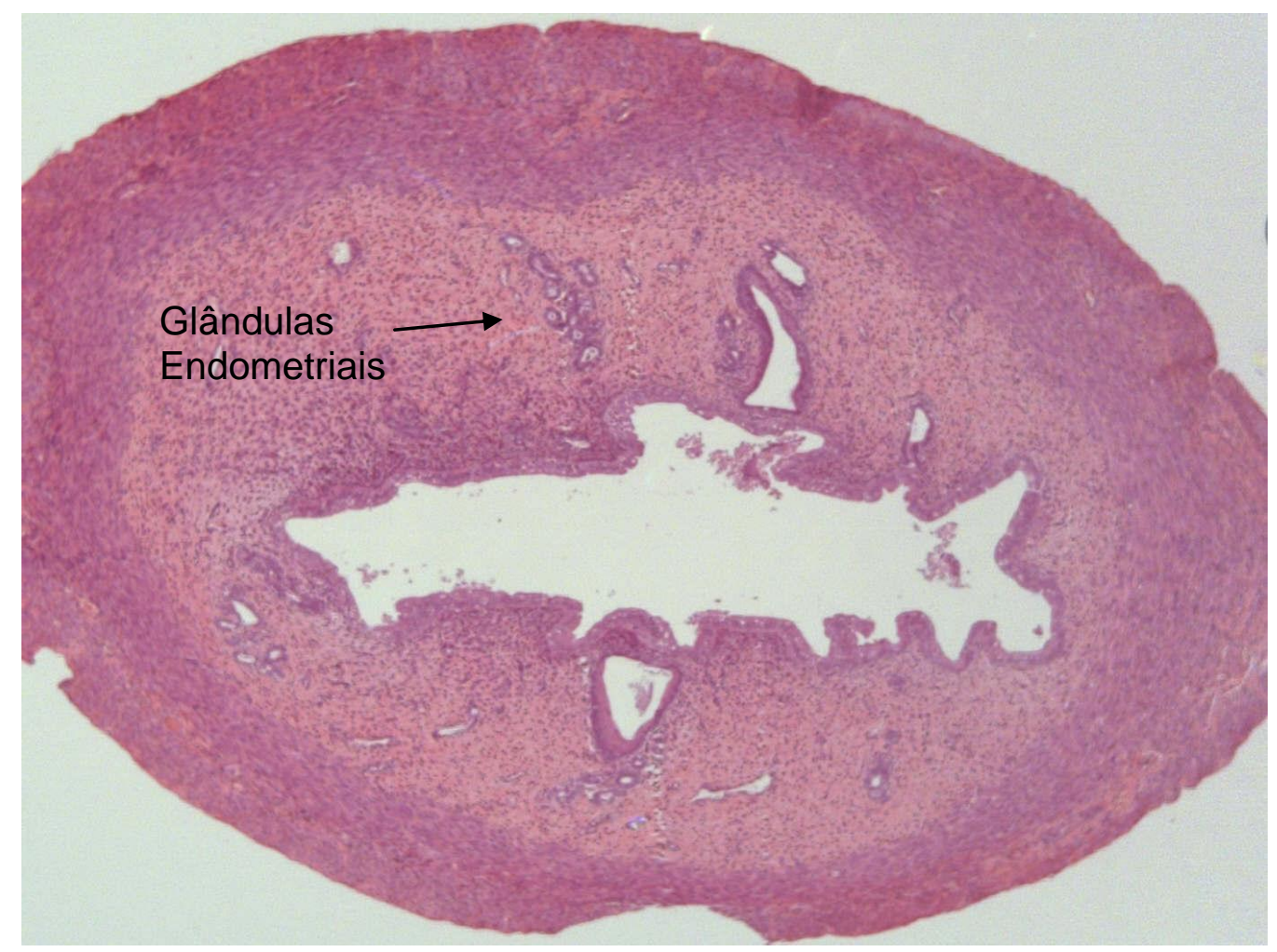


Figura 9. Avaliação histomorfométrica do corno uterino após injeção de ATA (ácido tricloroacético), demonstrando alterações significativas no número de glândulas. (HE 40x)

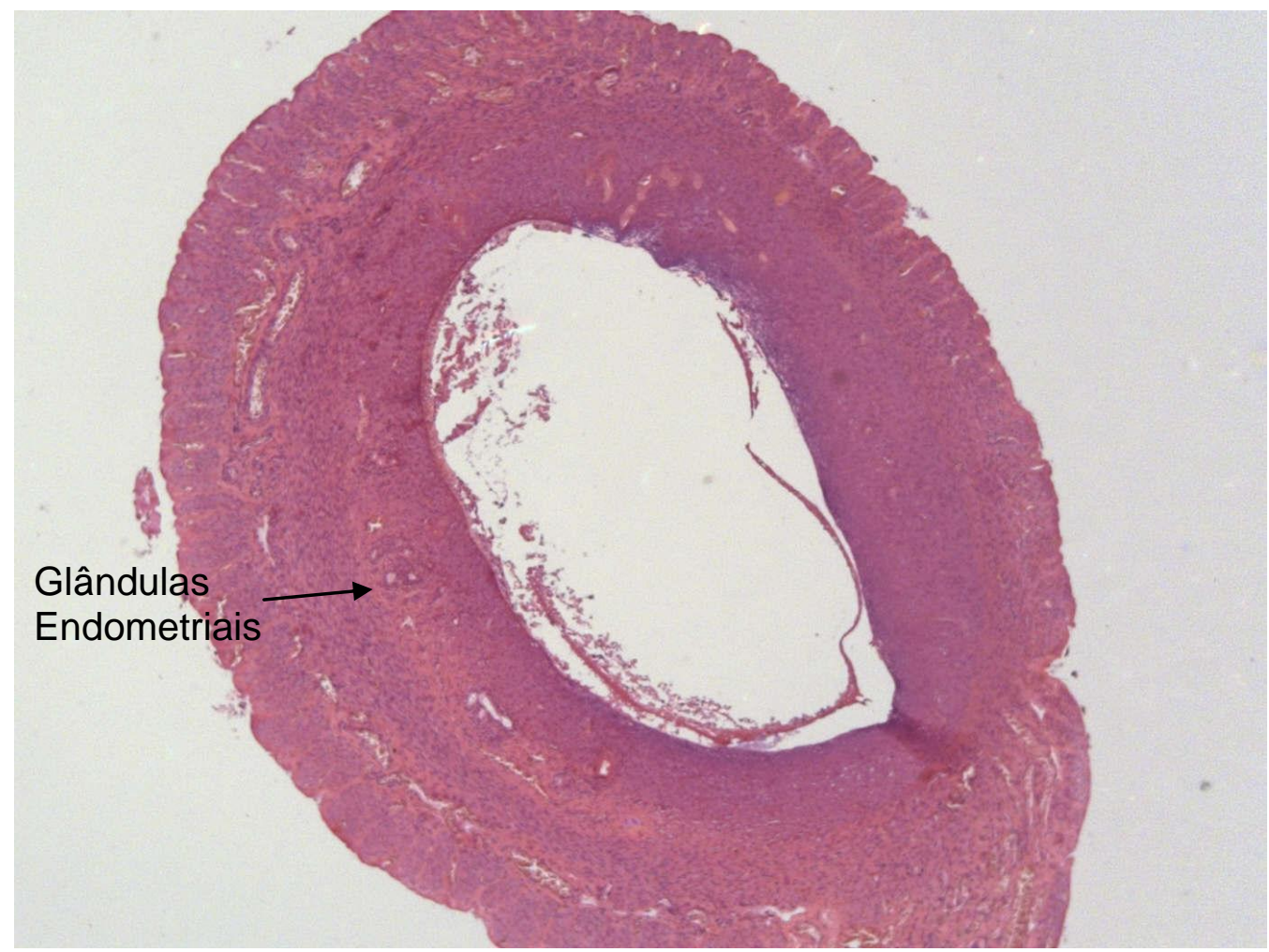

\subsubsection{Espessura miometrial}

A mediana da espessura miometrial após a injeção de ATA e SF foi de $0,25 \mathrm{~mm}(0,225-0,3)$ e $0,35 \mathrm{~mm}(0,3-0,425)$, respectivamente (Gráfico 4). 
Gráfico 4. Análise das alterações histomorfométricas na espessura miometrial no Grupo 1, nos cornos onde foram injetados ATA (ácido tricloroacético) e SF (soro fisiológico)

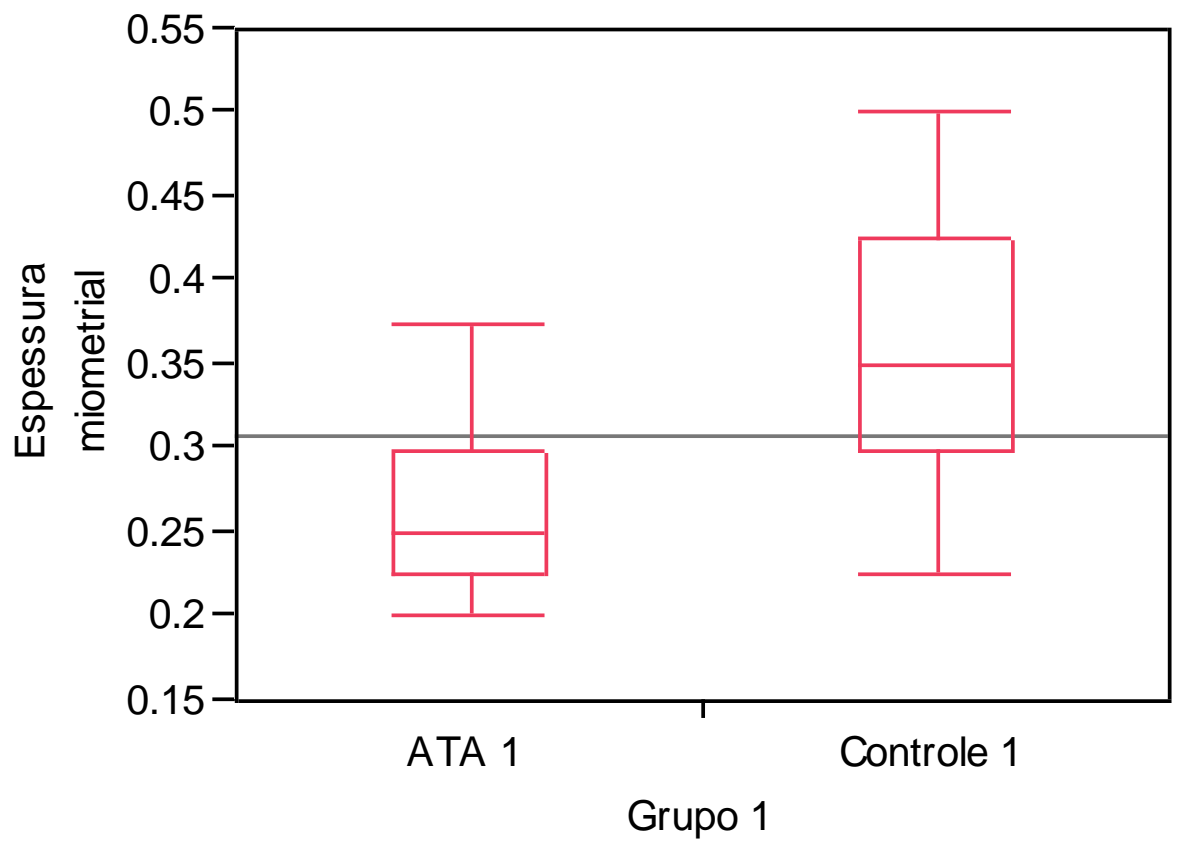

Houve diferença significante entre a espessura miometrial nos cornos uterinos onde foram injetados ATA e SF $(p=0,009)$ (Figuras 10 e 11). 
Figura 10. Avaliação histomorfométrica do corno uterino após injeção de SF (soro fisiológico), demonstrando ausência de alterações no miométrio. (HE $40 x)$

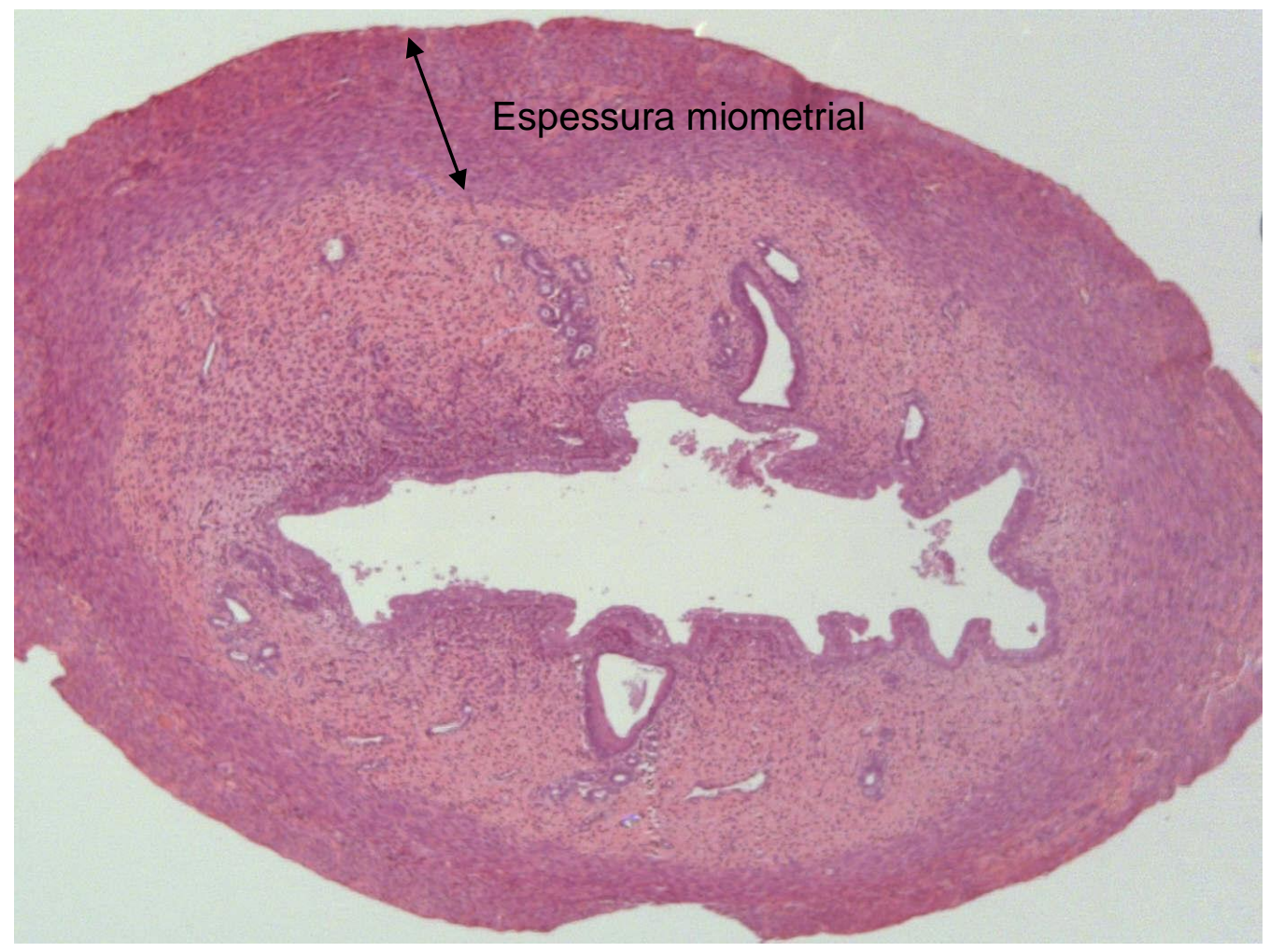


Figura 11. Avaliação histomorfométrica do corno uterino após injeção de ATA (ácido tricloroacético), demonstrando alterações significativas no miométrio. (HE 40x)

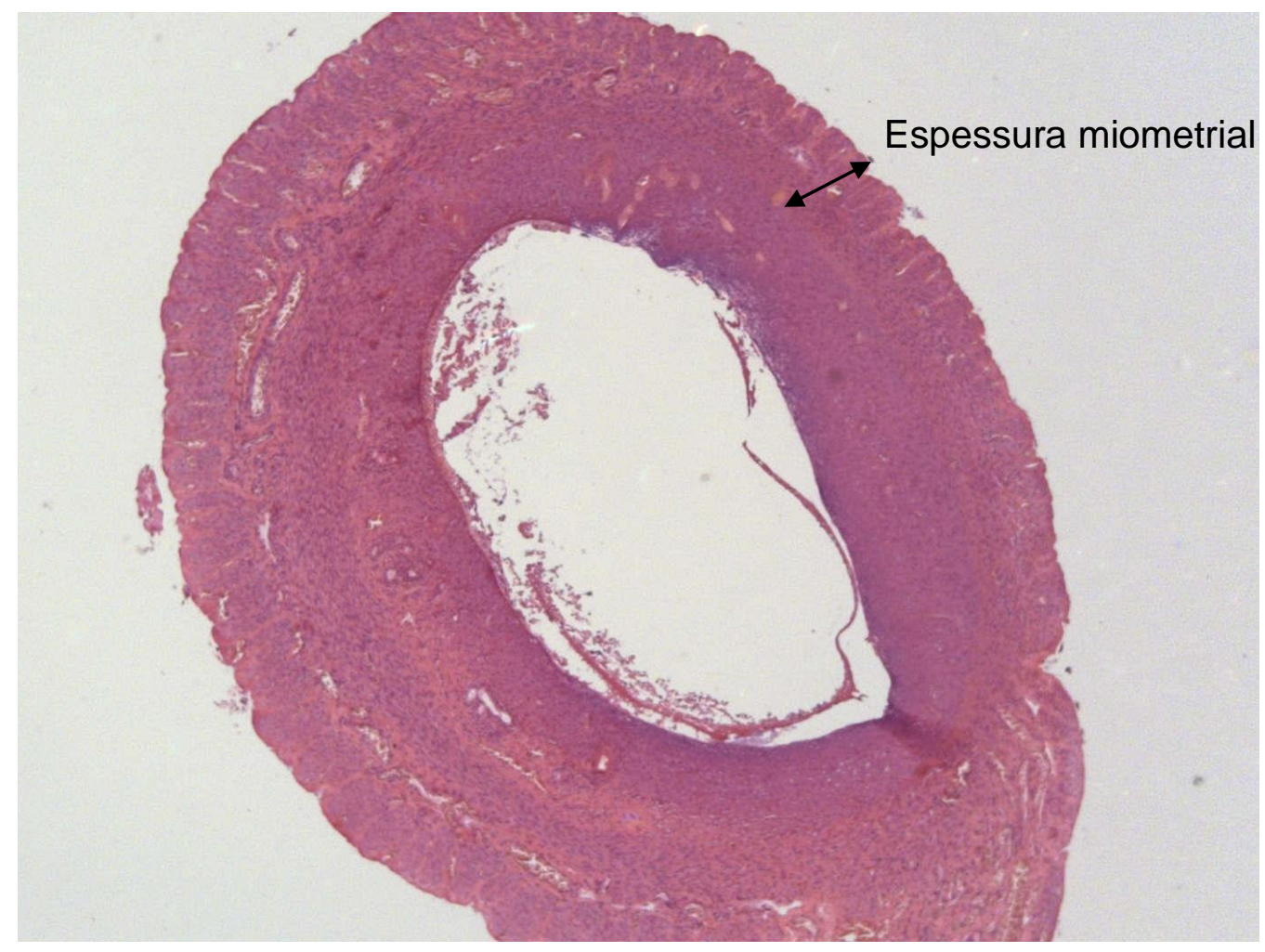

\subsection{Grupo 2}

Todos os animais do segundo grupo foram submetidos ao procedimento conforme descrito no desenho do projeto (Anexo 1). Os animais apresentaram recuperação anestésica sem intercorrências, alimentando-se normalmente no pós-operatório imediato. Quatro animais (27\%) morreram entre o $7^{\circ}$ e o $10^{\circ}$ dia após o procedimento. Nesses animais 
foram observadas perfuração intestinal e infecção intra-abdominal (Figuras 12 e 13).

Figura 12. Perfuração intestinal e infecção intra-abdominal em um dos ratos que morreram durante o seguimento do Grupo 2.

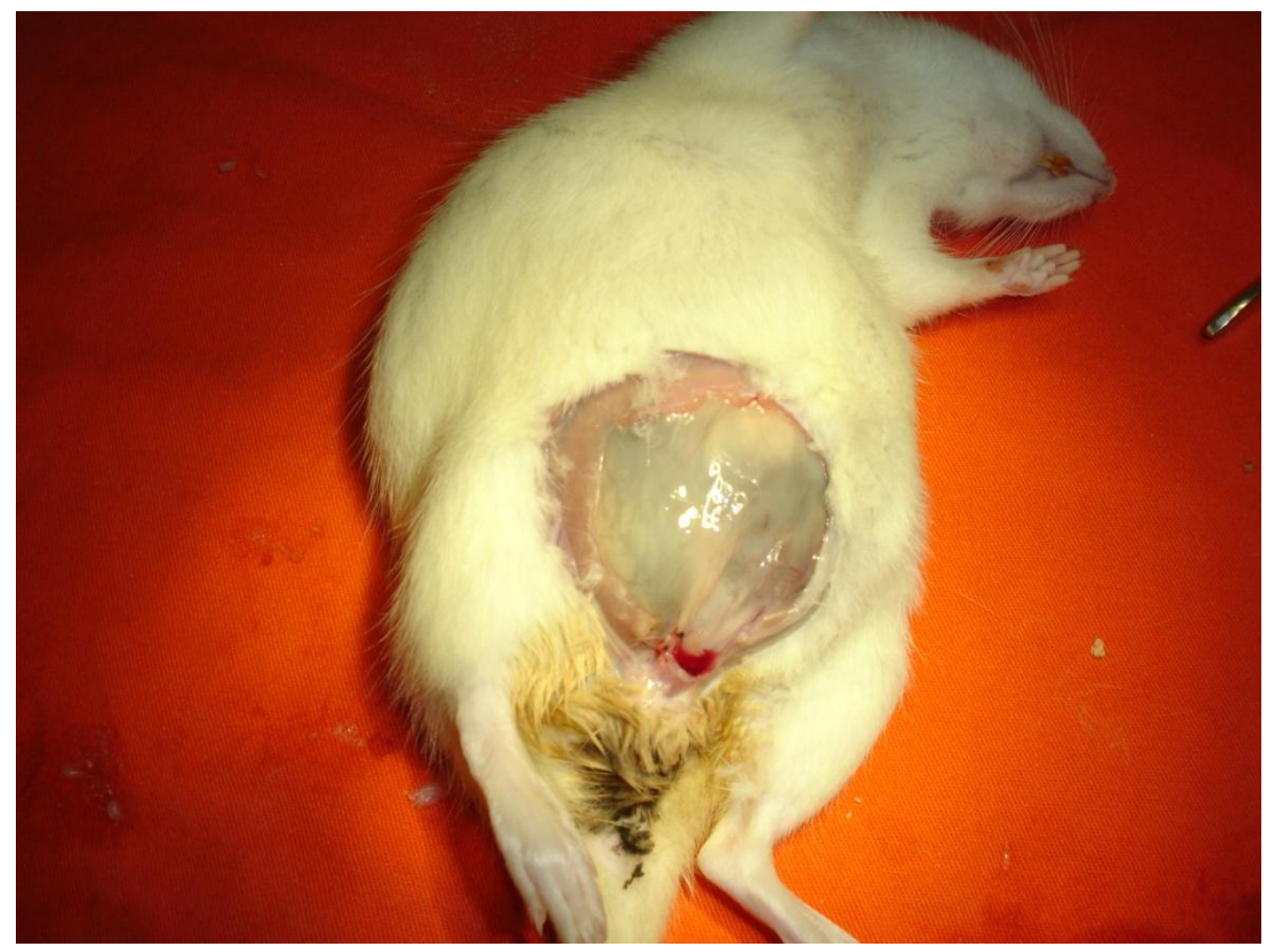


Figura 13. Identificação de perfuração intestinal e infecção intra-abdominal em um dos ratos que morreram durante o seguimento do Grupo 2.

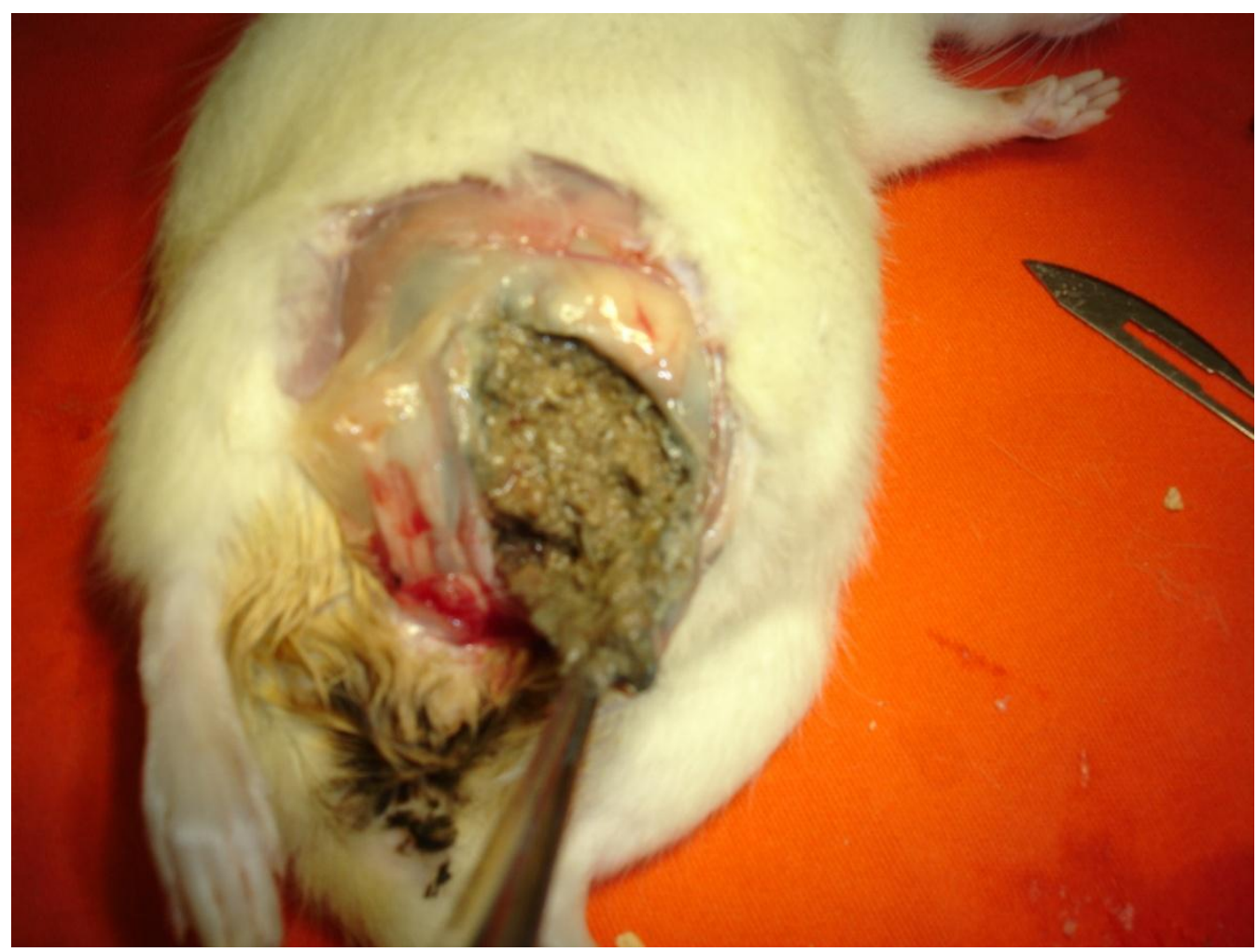

Em seis animais (40\%), o material obtido não pode ser avaliado devido à intensa destruição tecidual que impediu a análise dos parâmetros histomorfométricos previamente estabelecidos (Figura 14). 
Figura 14. Identificação de intensa destruição tecidual caracterizada por necrose coagulativa em toda espessura endometrial e miometrial.

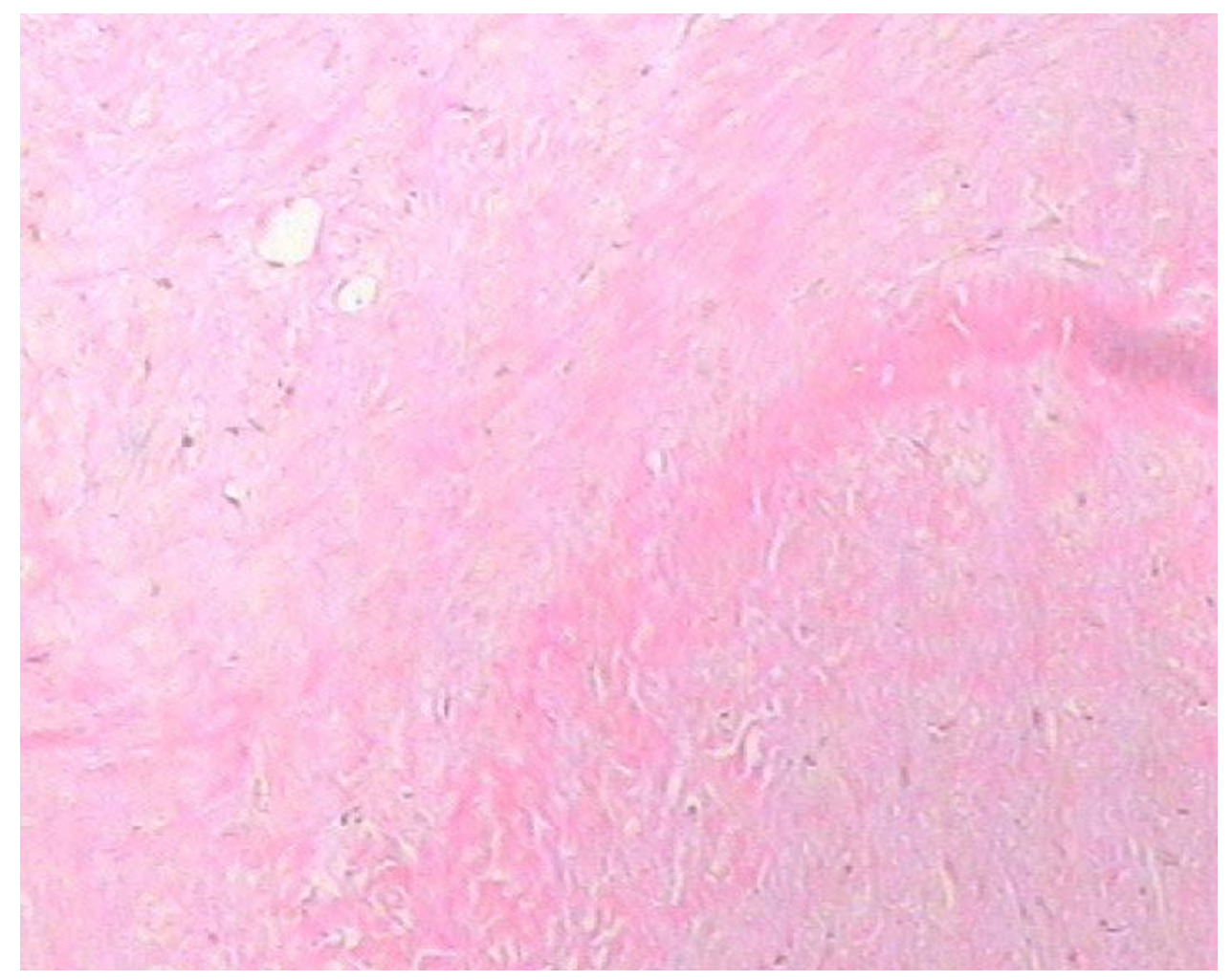

Os cinco animais restantes (33\%) foram sacrificados após retornarem ao ciclo estral, durante a fase de diestro. Os resultados relativos a esses animais foram analisados considerando-se as variáveis assinaladas na Tabela 2. 
Tabela 2. Comparação dos resultados histomorfométricos e histológicos das alterações teciduais nos cornos uterinos onde foram injetados ATA (ácido tricloroacético) e SF (soro fisiológico) no Grupo 2

\begin{tabular}{lccc}
\hline & ATA & SF & p value \\
& $0(0-0)$ & $0,05(0,05-0,05)$ & $<0,004^{*}$ \\
\hline $\begin{array}{l}\text { Espessura do epitélio } \\
\text { superficial do } \\
\text { endométrio (mm) }\end{array}$ & & \\
$\begin{array}{l}\text { Espessura do estroma } \\
\text { endometrial (mm) }\end{array}$ & $0,325(0,275-0,425)$ & $0,725(0,6-0,8)$ & $0,011^{*}$ \\
$\begin{array}{l}\text { Número de glândulas } \\
\text { por campo }\end{array}$ & $3(0-3,5)$ & $0,5(5,75-8)$ & $0,011^{*}$ \\
$\begin{array}{l}\text { Espessura miometrial } \\
\text { (mm) }\end{array}$ & $0,35(0,325-0,475)$ & $0,5(0,45-0,55)$ & $0,024^{*}$ \\
\hline $\begin{array}{l}\text { NOTA: Valores descritos são medianas e variações interquartis }(25 \%-75 \%) . \\
\text { *p<0,05 foi considerado estatisticamente significante }\end{array}$
\end{tabular}

\subsubsection{Espessura do epitélio superficial do endométrio}

A mediana da espessura do epitélio superficial do endométrio após a injeção de ATA e SF foi de $0 \mathrm{~mm}$ (0-0) e $0,05 \mathrm{~mm}$ (0,05-0,05), respectivamente (Gráfico 5). 
Gráfico 5. Análise das alterações histomorfométricas na camada epitelial do endométrio no Grupo 2, nos cornos onde foram injetados ATA (ácido tricloroacético) e SF (soro fisiológico)

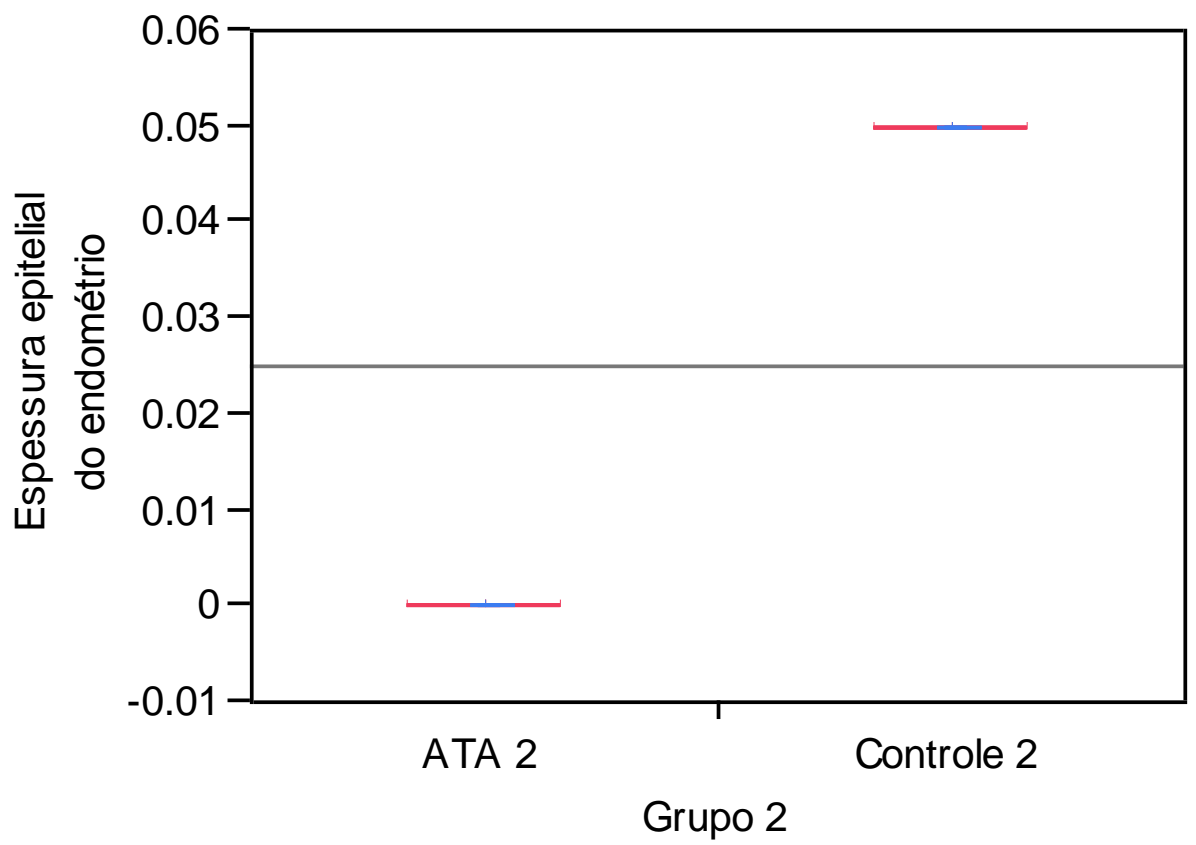

Houve diferença significante entre a espessura do epitélio superficial do endométrio nos cornos uterinos onde foram injetados ATA e SF $(p<0,004)$ (Figura 15). 
Figura 15. Avaliação histomorfométrica do corno uterino após injeção de ATA (ácido tricloroacético), demonstrando destruição completa do epitélio superficial do endométrio. (HE 200x)

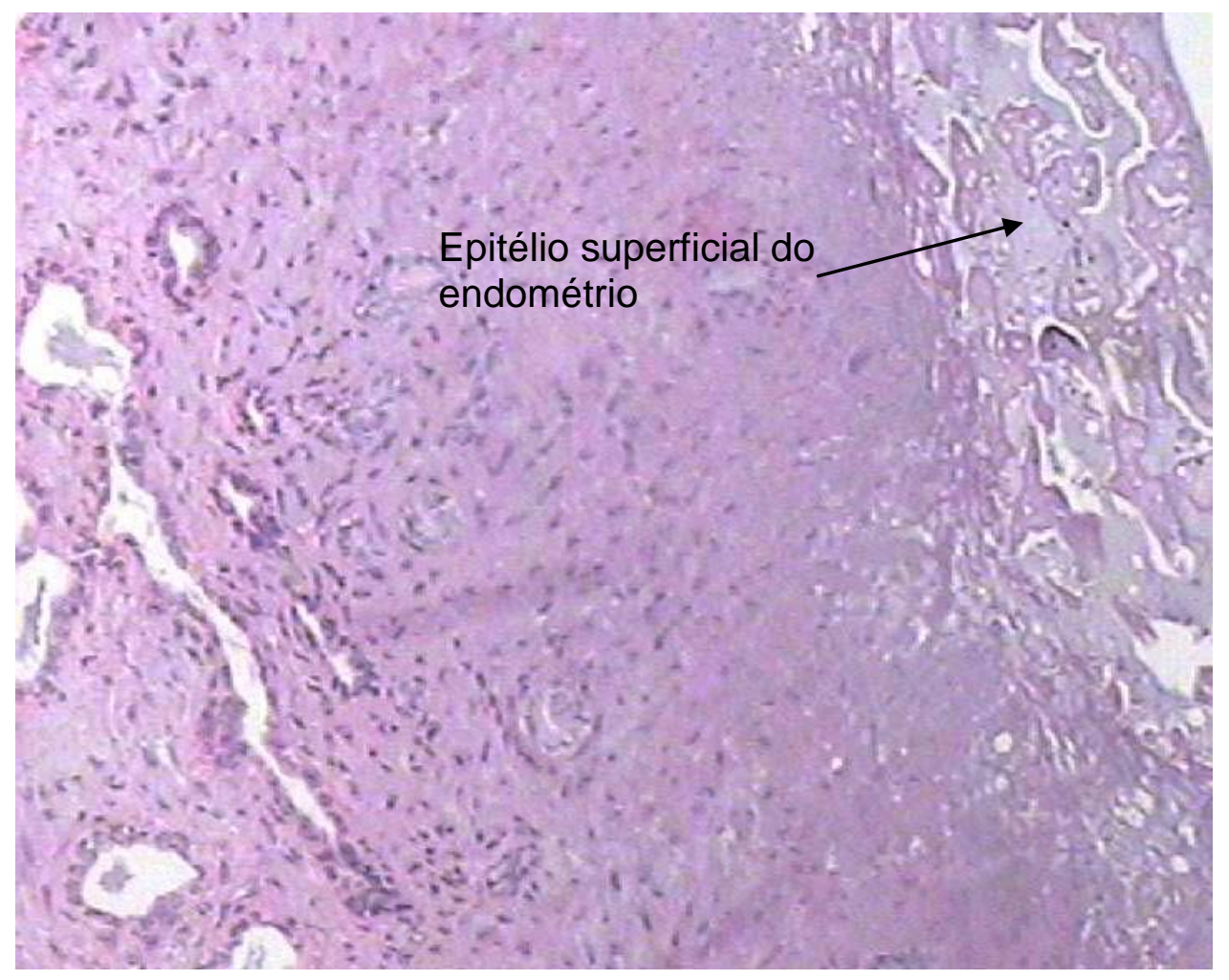

\subsubsection{Espessura do estroma endometrial}

A mediana da espessura do estroma endometrial após a injeção de ATA e SF foi de $0,325 \mathrm{~mm} \quad(0,275-0,425)$ e $0,725 \mathrm{~mm} \quad(0,6-0,8)$, respectivamente (Gráfico 6). 
Gráfico 6. Análise das alterações histomorfométricas na camada estromal do endométrio no Grupo 2, nos cornos onde foram injetados ATA (ácido tricloroacético) e SF (soro fisiológico).

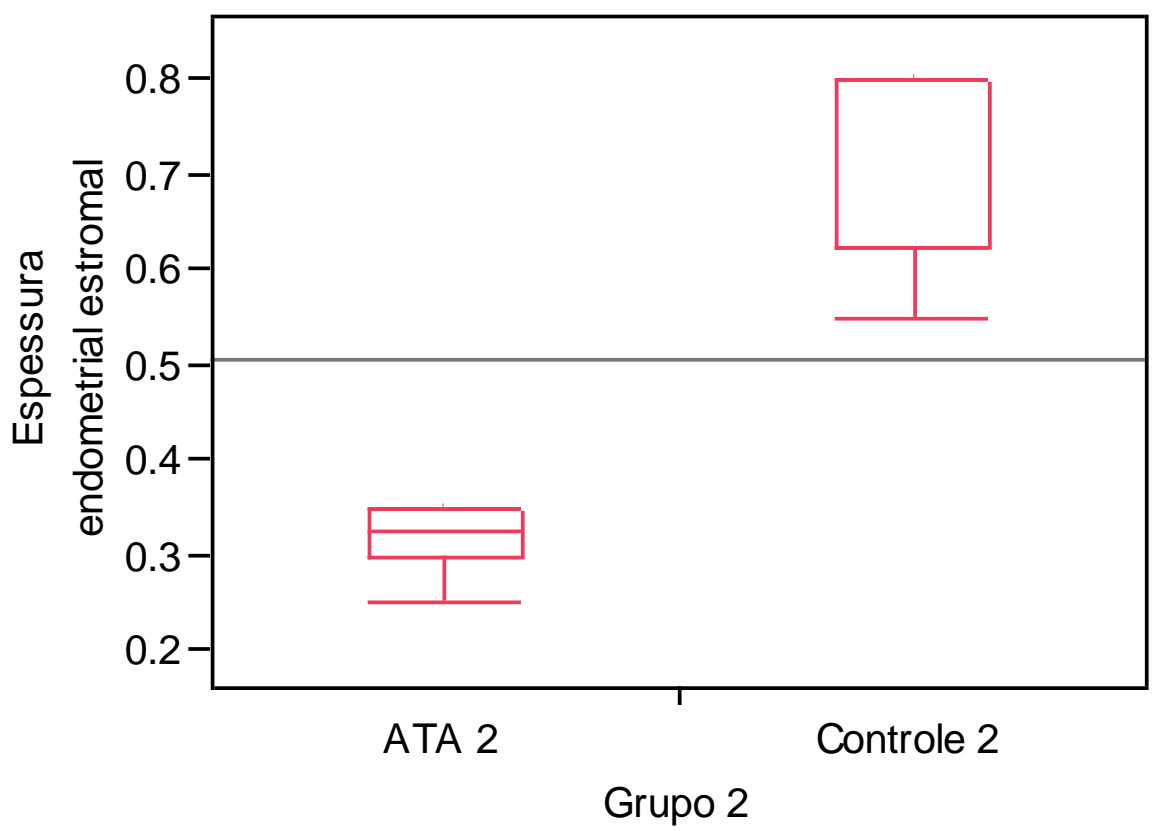

Houve diferença significante entre a espessura do estroma endometrial nos cornos uterinos onde foram injetados ATA e SF $(p=0,011)$ (Figuras 16 e 17). 
Figura 16. Avaliação histomorfométrica do corno uterino após injeção de SF (soro fisiológico), demonstrando ausência de alterações na camada estromal do endométrio. (HE 40x)

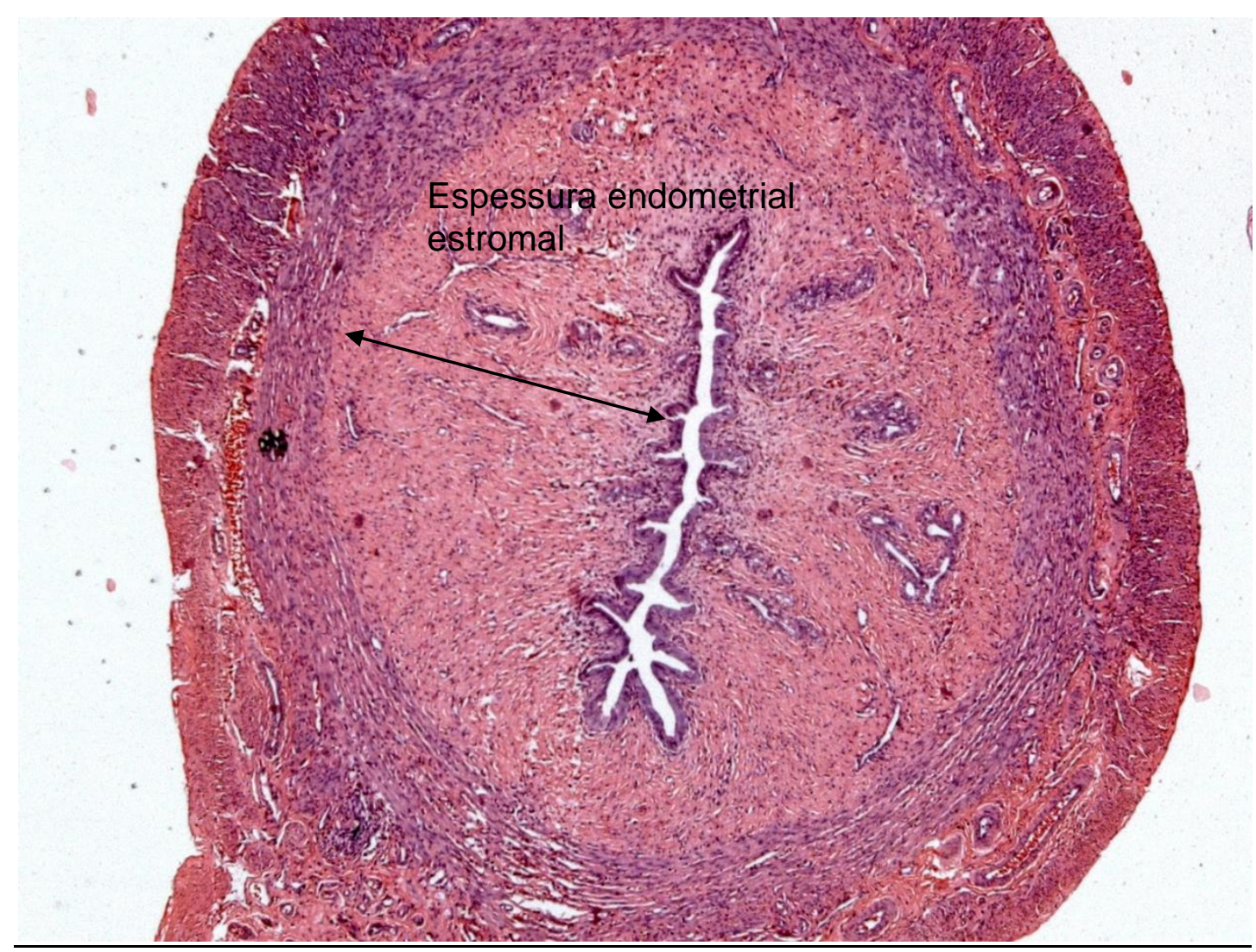


Figura 17. Avaliação histomorfométrica do corno uterino após injeção de ATA (ácido tricloroacético), demonstrando alterações significativas da espessura da camada estromal do endométrio. (HE 40x)

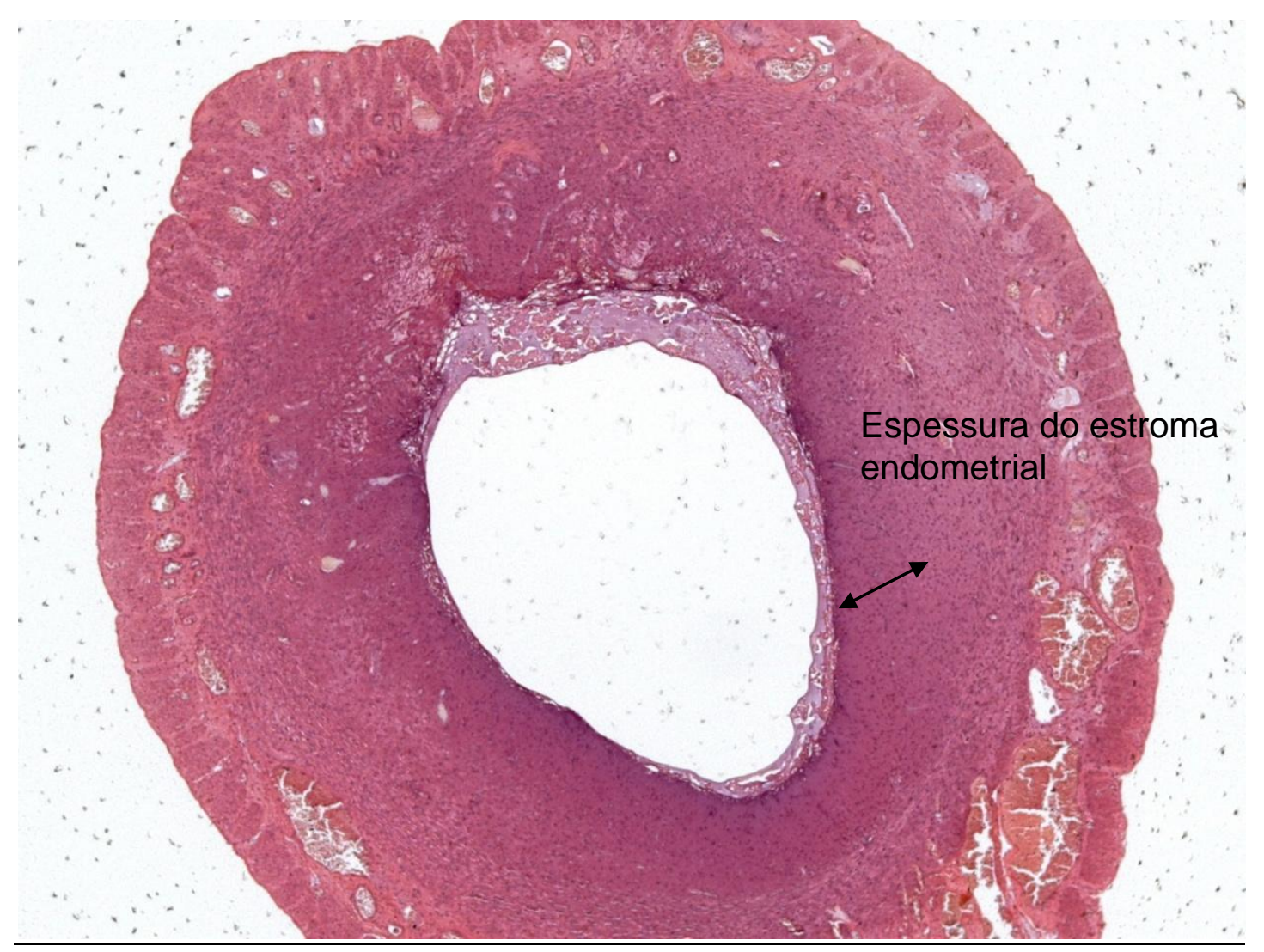

\subsubsection{Número de glândulas endometriais por campo}

A mediana do número de glândulas por campo de menor aumento após a injeção de ATA e SF foi de $3(0-3,5)$ e 6,5 (5,75-8), respectivamente (Gráfico 7). 
Gráfico 7. Análise das alterações histomorfométricas no número de glândulas por campo de menor aumento no Grupo 2, nos cornos onde foram injetados ATA (ácido tricloroacético) e SF (soro fisiológico)

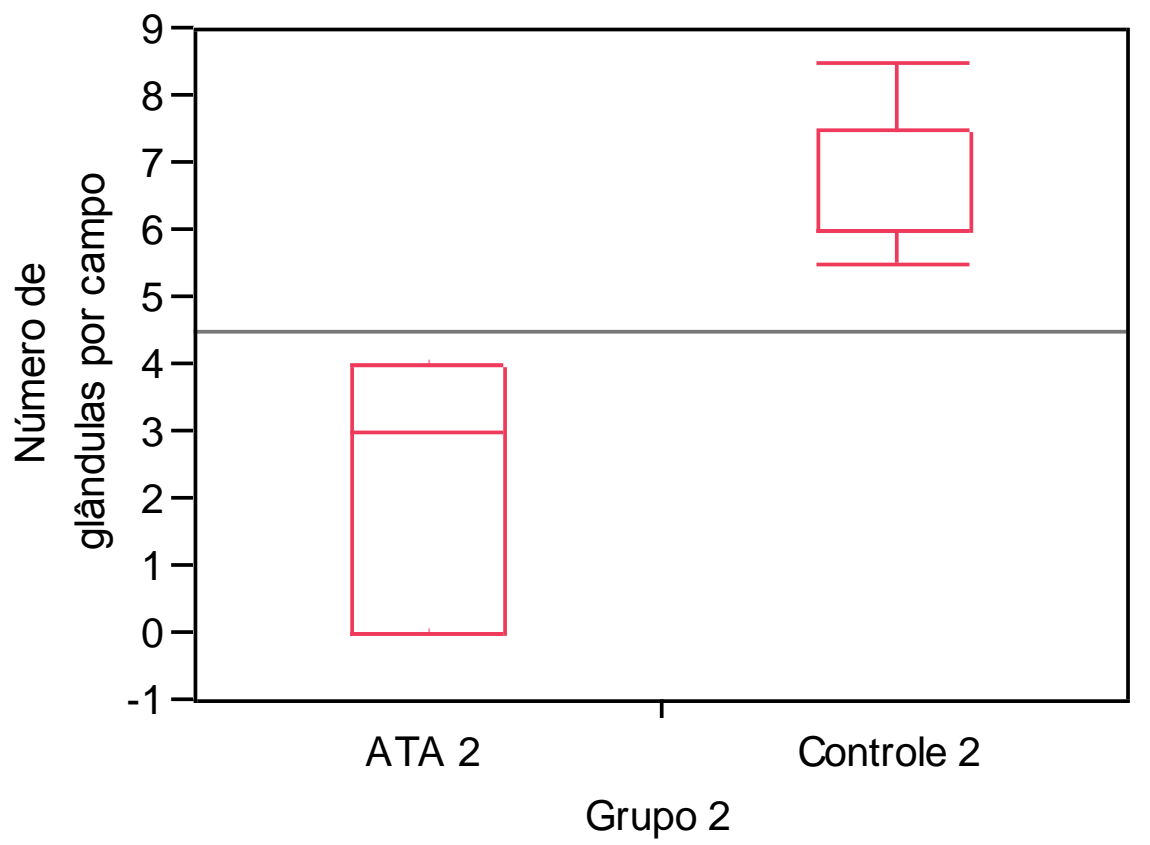

Houve diferença significante entre o número de glândulas por campo nos cornos uterinos onde foram injetados ATA e SF $(p=0,011)$ (Figuras 18 e 19). 
Figura 18. Avaliação histomorfométrica do corno uterino após injeção de SF (soro fisiológico), demonstrando ausência de alterações no número de glândulas endometriais. (HE 40x)

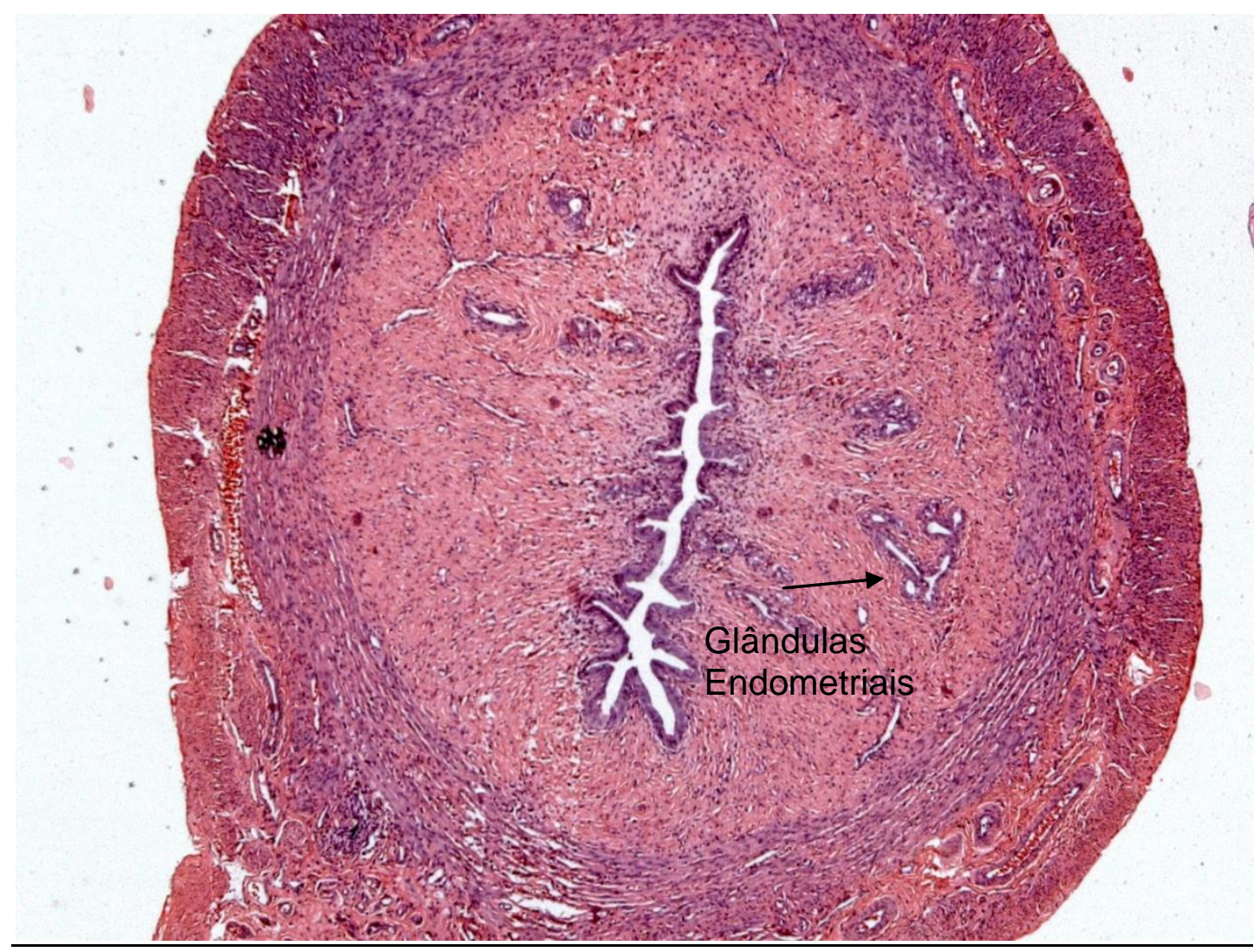


Figura 19. Avaliação histomorfométrica do corno uterino após injeção de ATA (ácido tricloroacético), demonstrando redução do número de glândulas endometriais. (HE 40x)

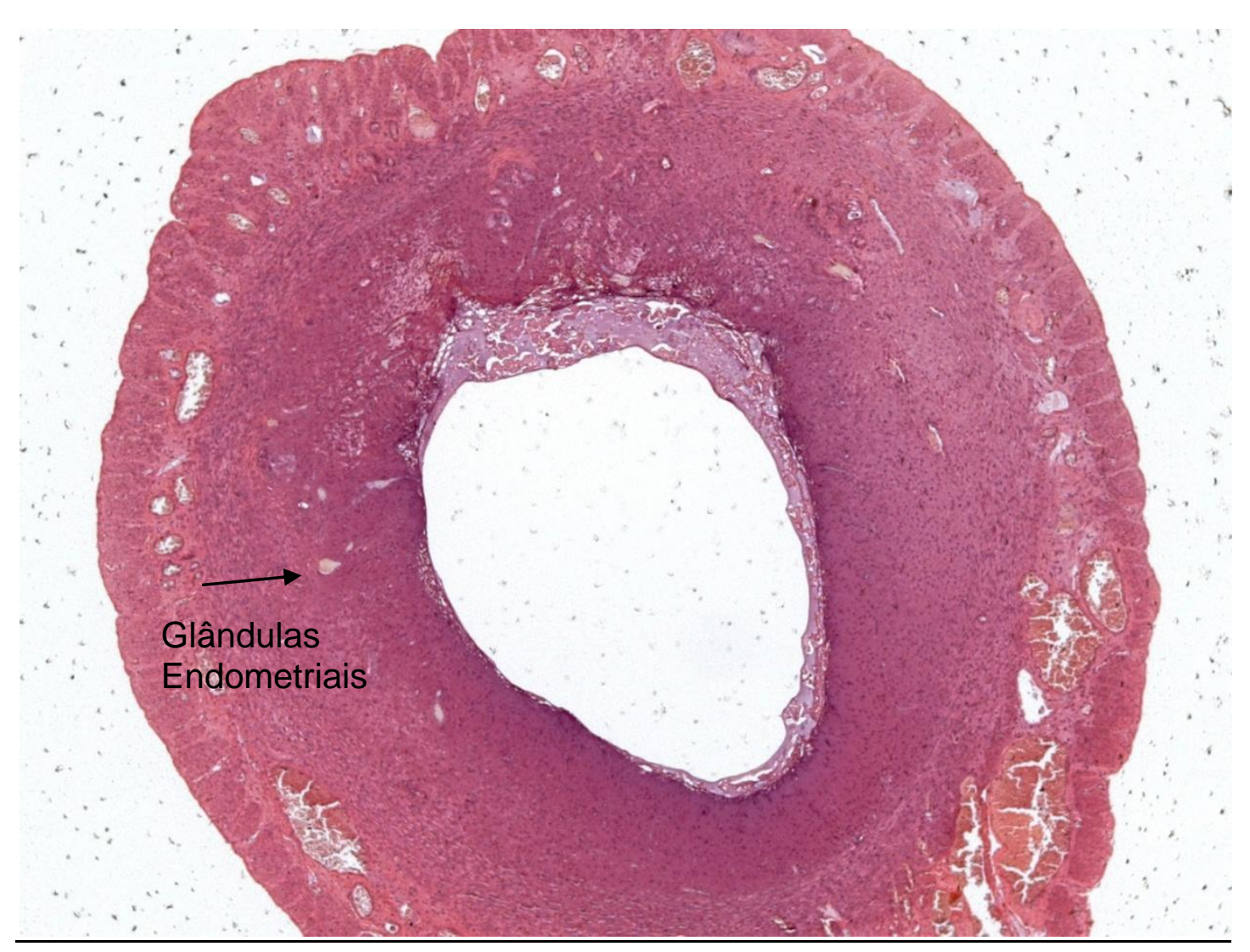


Figura 20. Avaliação histomorfométrica do corno uterino após injeção de ATA (ácido tricloroacético), demonstrando redução do número de glândulas. (HE 200x)

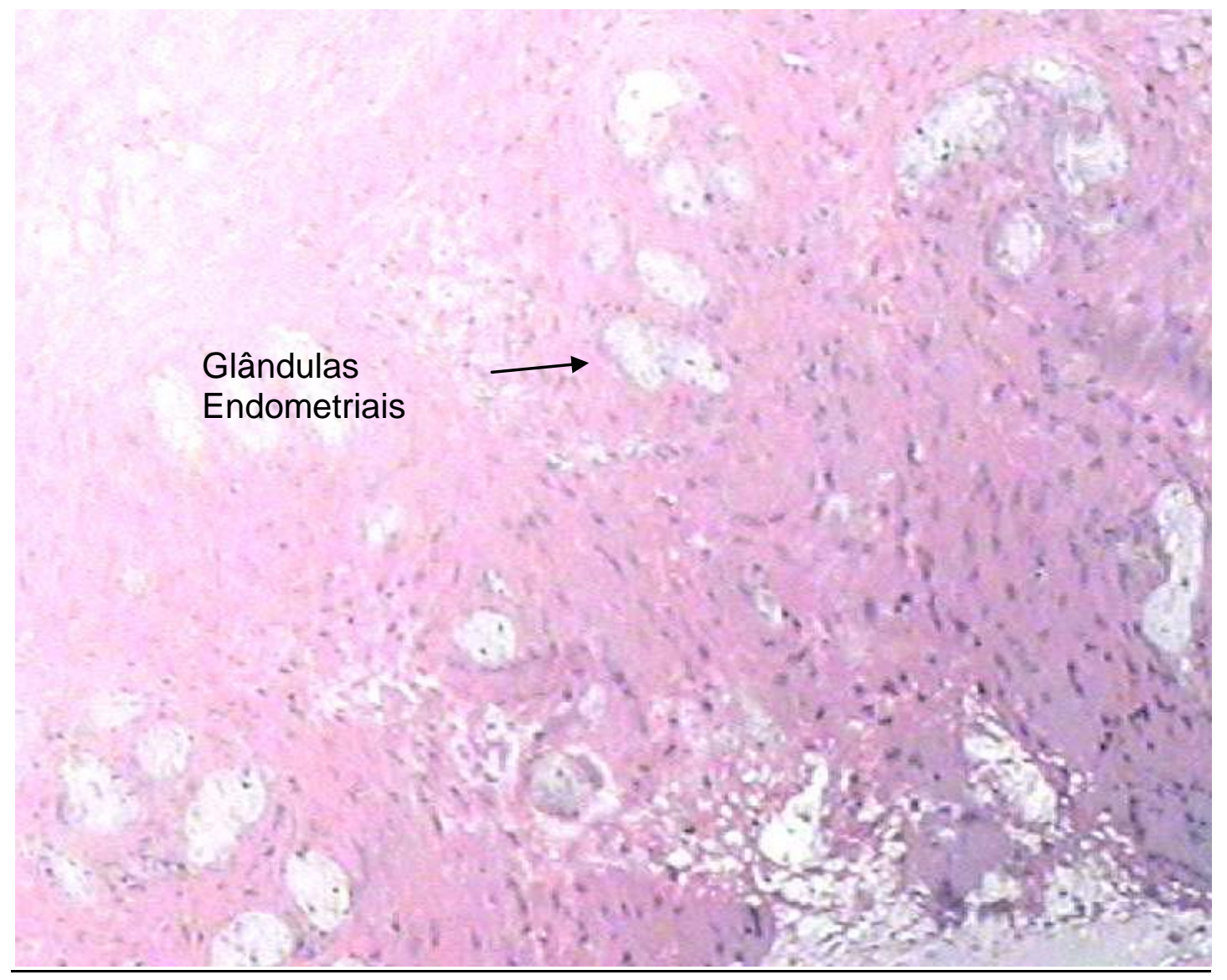

\subsubsection{Espessura miometrial}

A mediana da espessura miometrial após a injeção de ATA e SF foi de $0,35 \mathrm{~mm}(0,325-0,475)$ e $0,5 \mathrm{~mm}(0,45-0,55)$, respectivamente (Gráfico 8). 
Gráfico 8. Análise das alterações histomorfométricas na espessura miometrial no Grupo 2, nos cornos onde foram injetados ATA (ácido tricloroacético) e SF (soro fisiológico)

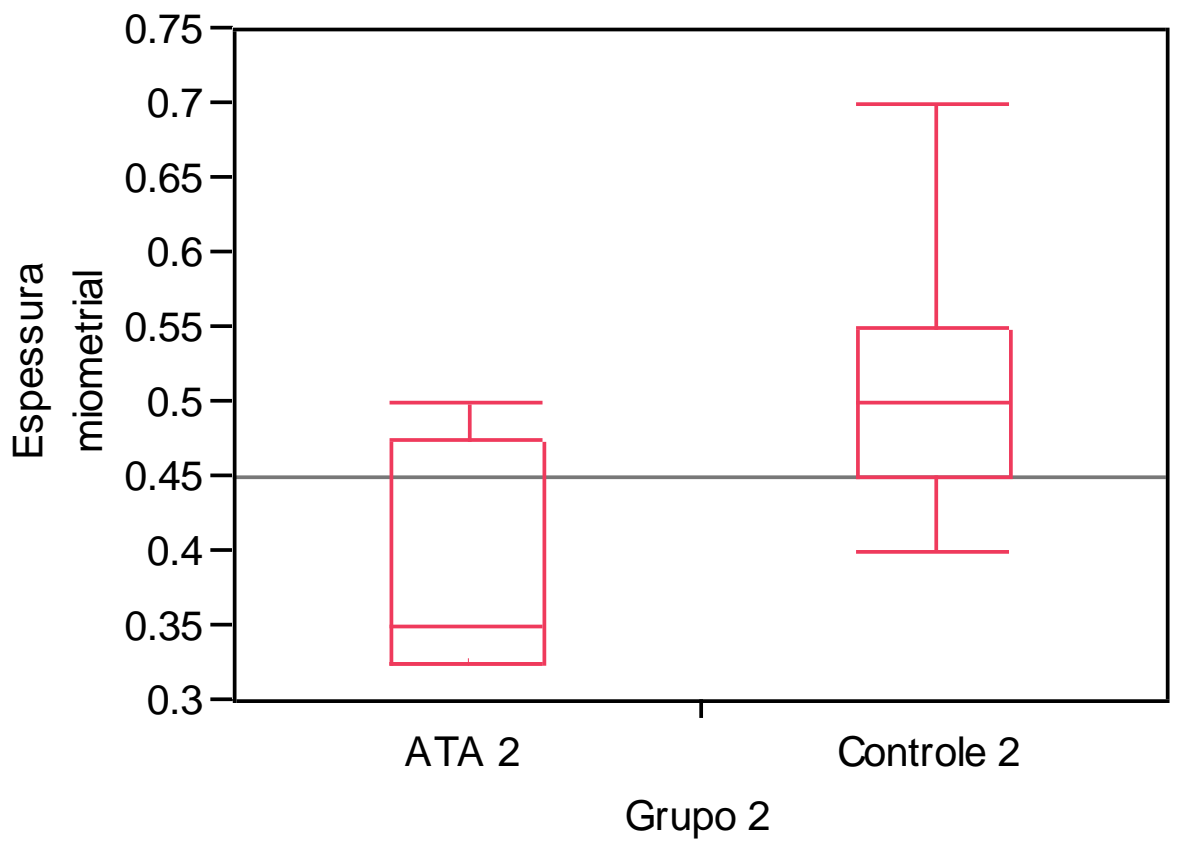

Houve diferença significante entre a espessura miometrial nos cornos uterinos onde foram injetados ATA e SF $(p=0,024)$ (Figuras 21 e 22). 
Figura 21. Avaliação histomorfométrica do corno uterino após injeção de SF (soro fisiológico), demonstrando ausência de alterações na camada do miométrio. (HE 40x)

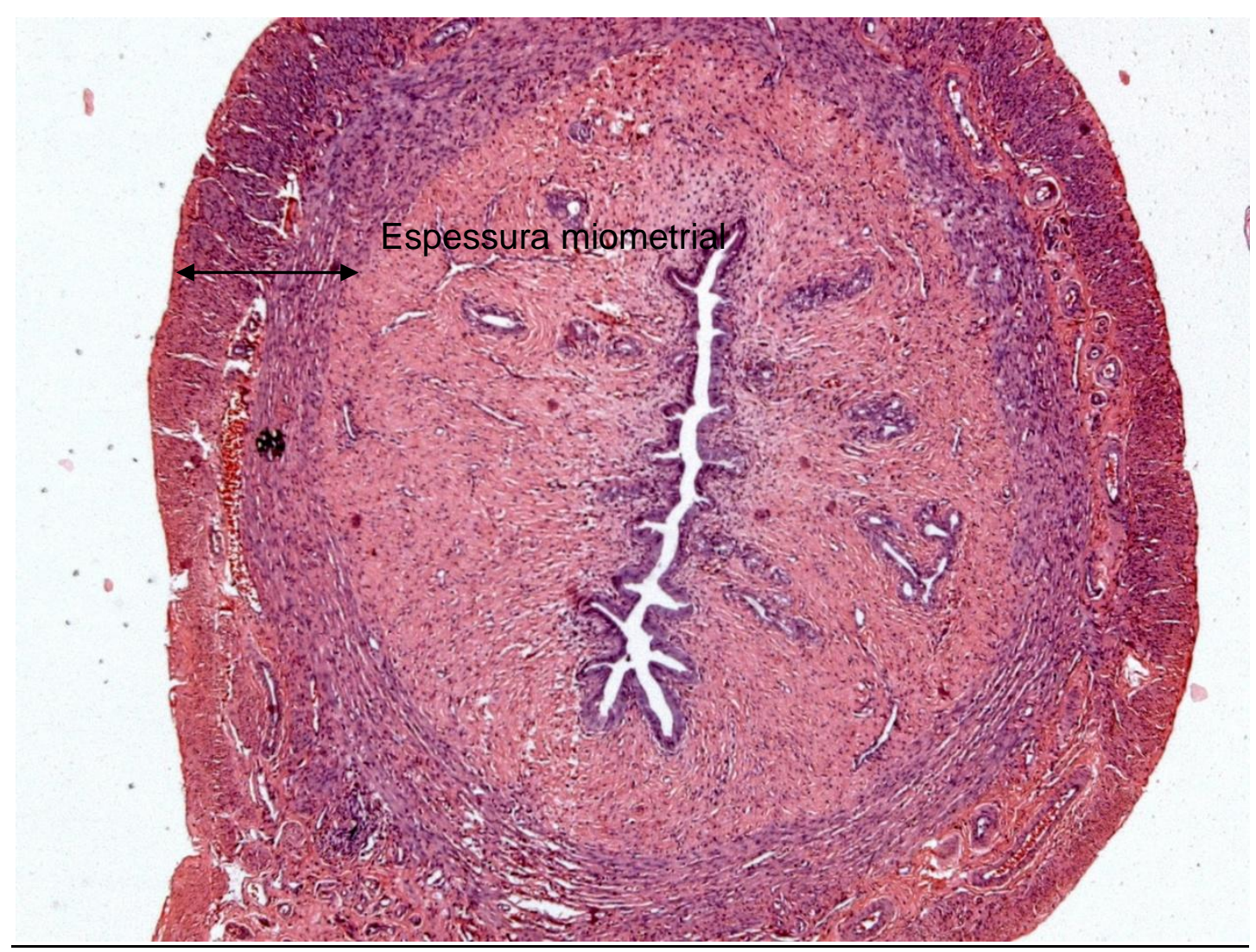


Figura 22. Avaliação histomorfométrica do corno uterino após injeção de ATA (ácido tricloroacético), demonstrando redução da espessura da camada do miométrio. (HE 40x)

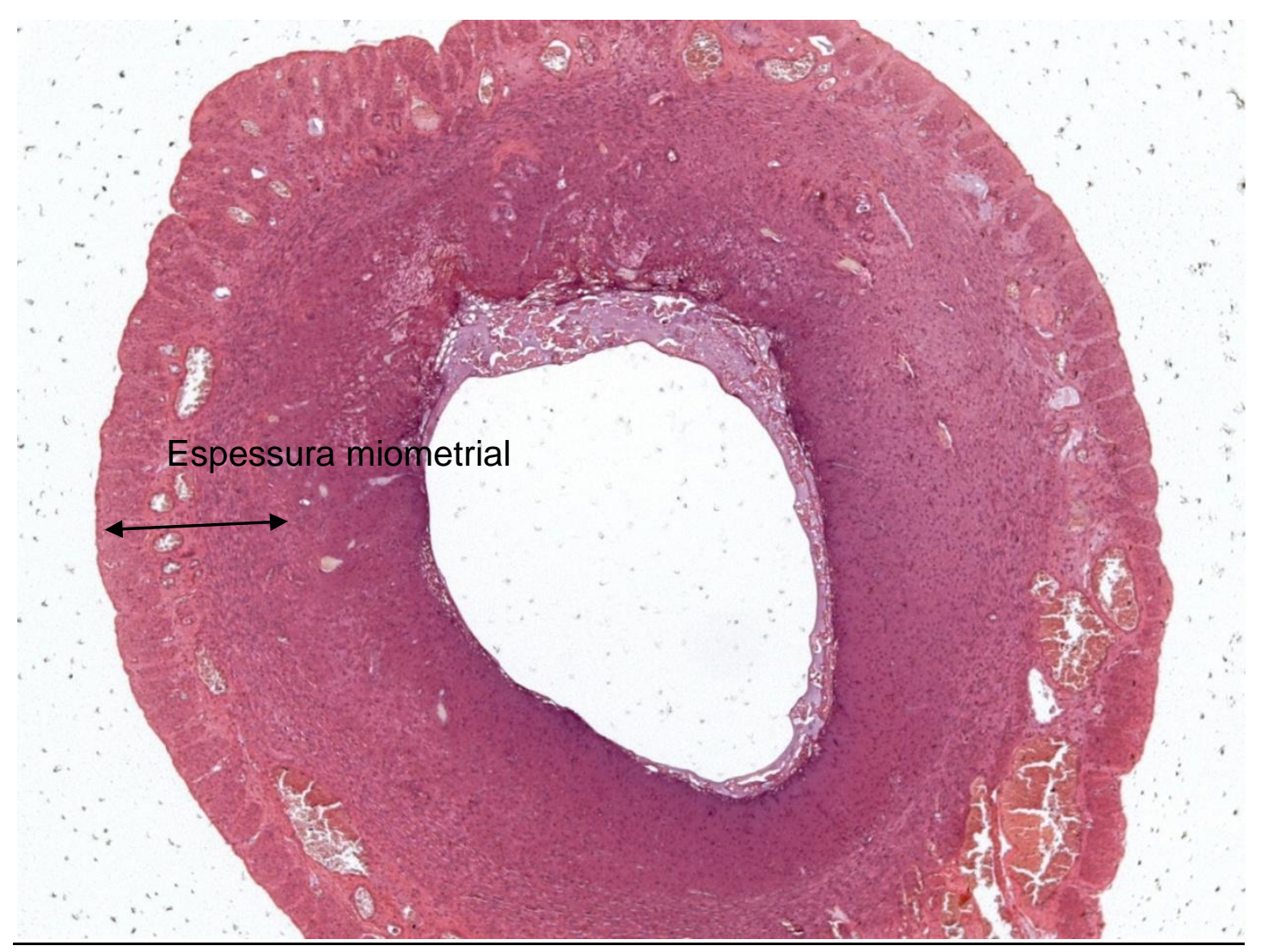

\subsection{Avaliação da regeneração endometrial nos Grupos 1 e 2}

Os parâmetros endometriais foram comparados entre os Grupos 1 e 2 considerando-se as variáveis contidas na Tabela 3. 
Tabela 3. Comparação dos resultados histomorfométricos e histológicos das alterações endometriais nos cornos onde foi injetado ATA entre os Grupos

Grupo $1 \quad$ Grupo $2 \quad p$ value

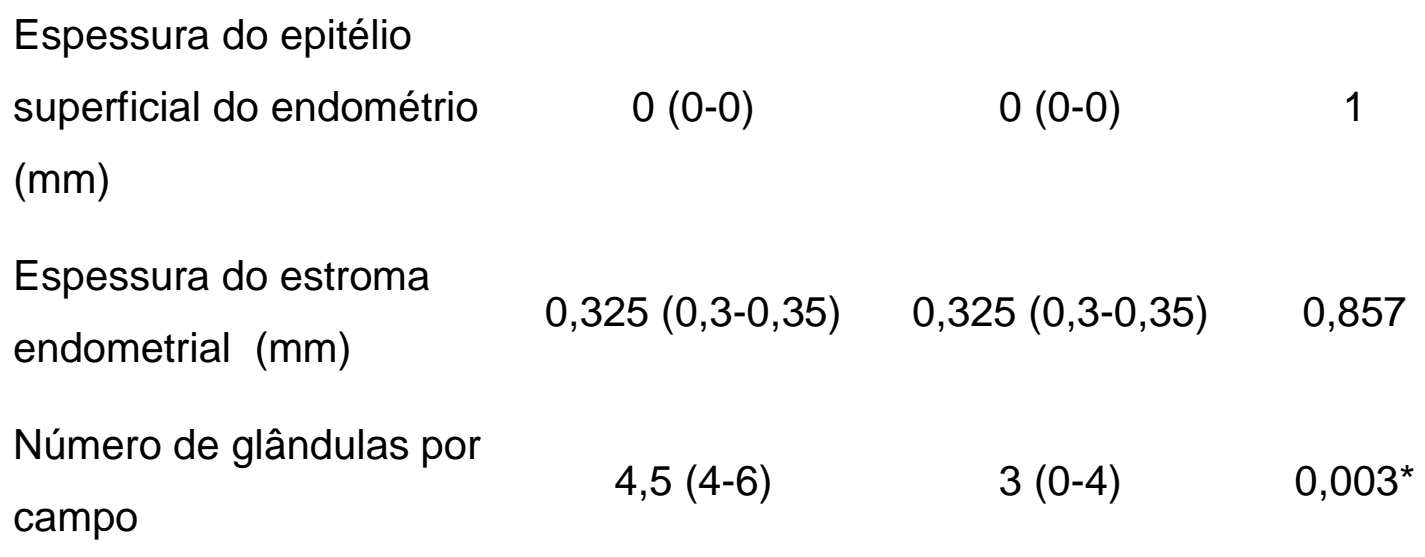

NOTA: Valores descritos são medianas e variações interquartis (25\%-75\%). ${ }^{*} p<0,05$ foi considerado estatisticamente significante

\subsubsection{Espessura epitelial do endométrio}

A mediana da espessura do epitélio superficial do endométrio após a injeção de ATA nos Grupos 1 e 2 foi de $0 \mathrm{~mm}$ (0-0) e $0 \mathrm{~mm}(0-0)$, respectivamente (Gráfico 9). Não ocorreu diferença significante na espessura do epitélio superficial do endométrio nos cornos uterinos onde foi injetado ATA entre os grupos $(p=1)$. 
Gráfico 9. Análise das alterações histomorfométricas na camada epitelial do endométrio entre os Grupos, nos cornos onde foi injetado ATA (ácido tricloroacético)

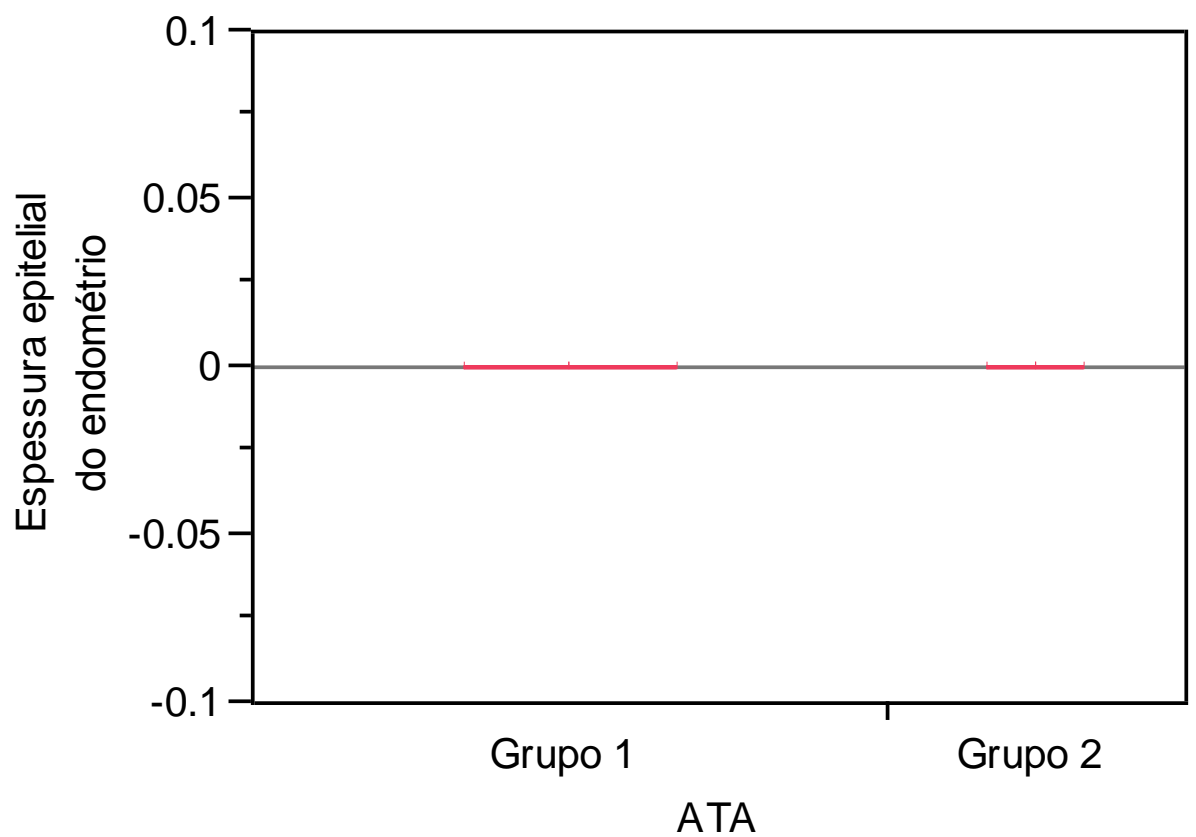

\subsubsection{Espessura do estroma endometrial}

A mediana da espessura do estroma endometrial após a injeção de ATA nos Grupos 1 e 2 foi de 0,325mm (0,3-0,35) e 0,325mm (0,3-0,35), respectivamente (Gráfico 10). Não ocorreu diferença significante entre a espessura do estroma endometrial nos cornos uterinos onde foi injetado ATA entre os dois grupos $(p=0,857)$. 
Gráfico 10. Análise das alterações histomorfométricas na camada estromal do endométrio entre os Grupos, nos cornos onde foi injetado ATA (ácido tricloroacético)

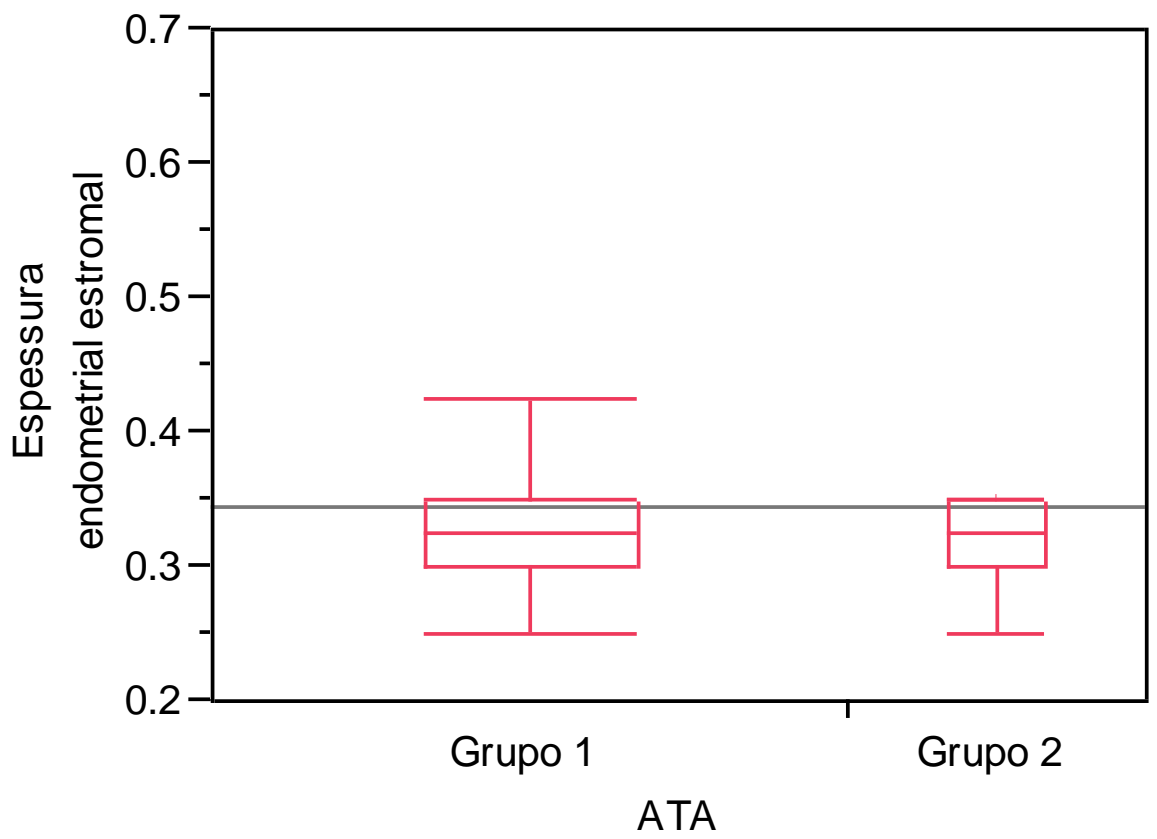

\subsubsection{Número de glândulas por campo}

A mediana do número de glândulas por campo de menor aumento após a injeção de ATA nos Grupos 1 e 2 foi de 4,5 (4-6) e 3 (0-4), respectivamente (Gráfico 11). 
Gráfico 11. Análise das alterações histomorfométricas no número de glândulas por campo de menor aumento entre os Grupos, nos cornos onde foi injetado ATA (ácido tricloroacético)

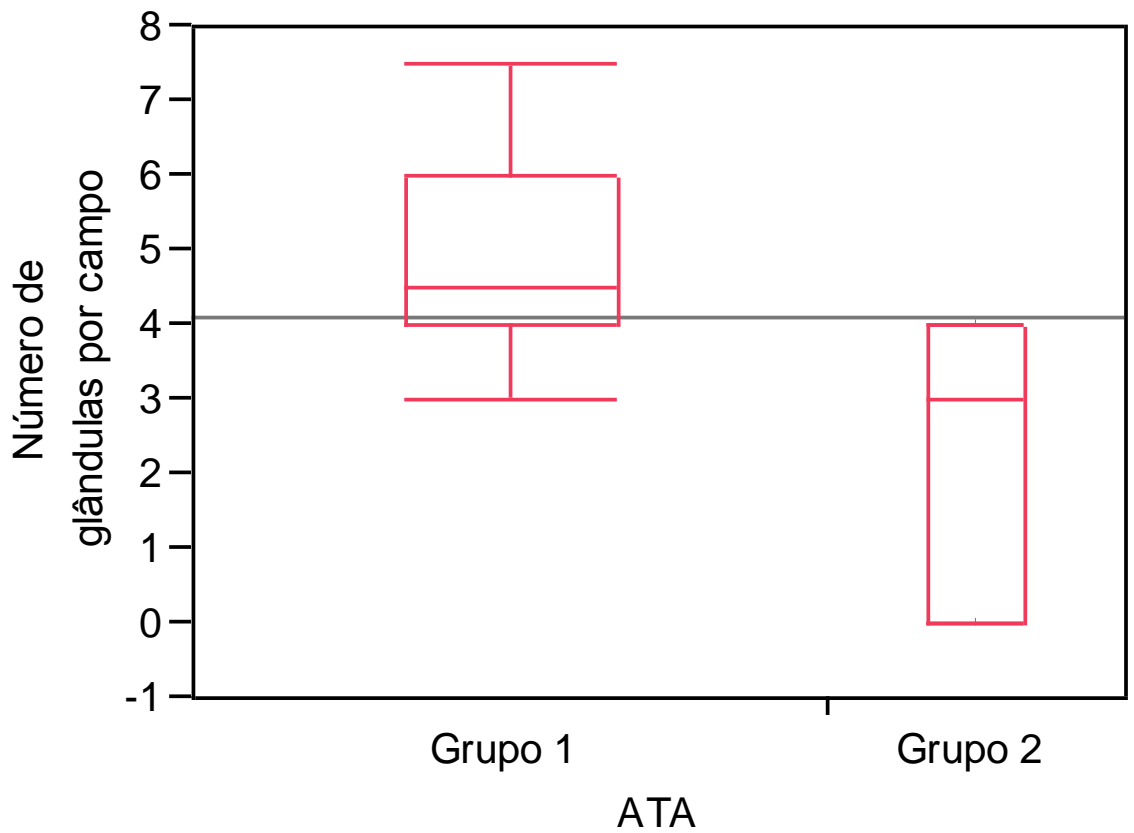

Houve diferença significante entre o número de glândulas por campo nos cornos uterinos onde foi injetado ATA entre os grupos $(p=0,003)$. 
5. DISCUSSÃO 


\section{DISCUSSÃO}

O sangramento uterino disfuncional é uma importante condição patológica feminina responsável por grande quantidade de consultas anuais ginecológicas no mundo e fonte considerável de custos ao sistema de saúde 20. Na falha do tratamento hormonal, a destruição endometrial se coloca como opção terapêutica importante. No entanto, o alto custo e as dificuldades técnicas do emprego da ablação endometrial pelos métodos correntemente empregados, têm limitado seu uso a casos de exceção.

Neste trabalho propusemo-nos a desenvolver o modelo de ablação endometrial em ratas adultas, bem como, avaliar os efeitos histológicos e histomorfométricos causados pelo ácido tricloroacético no útero de ratas, assim como a regeneração endometrial. Em nosso estudo, na fase aguda após a injeção de ATA, todos os animais sobreviveram ao procedimento. A substância foi claramente superior à solução utilizada nos grupos controles, uma vez que demonstrou capacidade destrutiva quando analisadas a espessura do epitélio superficial, a espessura do estroma, o número de glândulas por campo e a espessura miometrial.

Poucos estudos sobre a utilização de ATA na ablação endometrial foram descritos até o presente momento. Em trabalho realizado com 90 pacientes com SUD na Turquia, os autores administraram ATA com haste de algodão na cavidade endometrial e compararam o procedimento sozinho ou após a administração de danazol ou goserelina. Os resultados mostraram eficácia em curto prazo no processo de ablação e melhora do quadro clínico e nos índices hematimétricos. No entanto, houve melhor resultado quando o 
ATA era precedido do uso de danazol ou goserelina ${ }^{25}$. Um segundo trabalho, comparou a instilação de ATA, isolado ou em associação com acetato de leuprolide, no tratamento do SUD. Houve monitorização clínica no $3^{\circ}, 6^{\circ}$ e $12^{\circ}$ mês após o procedimento. Após um ano, os autores realizaram biópsia endometrial para avaliar o efeito a longo prazo. Quando se utilizou ATA isolado ou associado ao leuprolide, os efeitos de atrofia endometrial foram semelhantes. No entanto, os autores relataram que os índices de amenorréia obtidos foram inferiores aos conseguidos por ablação por laser 2. Embora possa se reconhecer a possível aplicabilidade do método proposto, a postura dos autores dos trabalhos citados de iniciar os experimentos in anima nobile traz considerações éticas importantes. Por esse motivo decidimos desenvolver um modelo animal de ablação endometrial possibilitando avaliar os efeitos histológicos e histomorfométricos causados pelo ATA.

O ácido tricloroacético é um agente cáustico obtido da oxidação do hidrato cloral com o ácido nítrico ${ }^{26}$ e é comumente utilizado para tratar verrugas genitais, na concentração de 40 a 100\%. Sua ação provoca erosão da pele e da membrana mucosa, leva à precipitação de proteínas, necrose coagulativa da células da epiderme e necrose do colágeno nas camadas mais profundas. Geralmente, o produto não é absorvido sistemicamente. Boa parte da experiência acumulada sobre o uso do ATA vem da área dermatológica, uma vez que há tempos ele é usado para tratamento de lesões de pele proliferativas e atróficas através de descamação e posterior reepitelização ${ }^{23}$. Quando administrado de forma controlada, provoca 
destruição local limitada, mas sua aplicação deve ser criteriosa, uma vez que o volume excedente pode levar à lesão de órgão adjacentes ${ }^{27}$.

A ação a curto prazo do ácido no endométrio e no miométrio dos animais estudados demonstra sua capacidade destrutiva. A espessura do epitélio endometrial superficial foi significativamente menor nos animais tratados. Além disso, a espessura do estroma e o número de glândulas endometriais mostraram-se menores nos animais submetidos ao ácido, evidenciando o grau de penetração da substância em camadas mais profundas no endométrio. Esse efeito é desejável, uma vez que o objetivo é a destruição da camada funcional do endométrio e, por conseguinte, a diminuição do sangramento, caso seu uso venha a ser aplicado na prática clínica. Outro ponto de interesse é que a camada miometrial também mostrou espessura significantemente menor nos cornos uterinos submetidos ao tratamento com ATA. Isso demonstra que a penetração do ácido, embora naquele momento não fosse tão intensa e não demonstrasse diferenças tão marcantes quanto aos parâmetros anteriormente descritos, atingiu camadas mais profundas do útero e levou a destruição da camada muscular. Cabe aqui uma crítica ao modelo, uma vez que a quantidade de ácido injetada no grupo de estudo foi definida por meio do projeto piloto. Parece, no entanto, ter havido um efeito de retardo da ação do ATA ou uma espessura muito delgada da parede uterina no modelo animal de ratas, o que levou a esse efeito tardio indesejável. Outra possibilidade é a de que o veículo utilizado, não tenha sido o mais adequado. Nos estudos em humanos citados anteriormente, usou-se ATA com aplicação por hastes de algodão ${ }^{25}$ ou por 
instilação ${ }^{2}$. Em nosso estudo, houve a aplicação direta da solução com o ácido no corno uterino a ser estudado. Uma vez que se busca uma formulação prática para potencial uso em humanos, uma possibilidade interessante seria o teste de formulações que pudessem liberar o ATA de maneira mais controlada, como, por exemplo, uma solução de gel contendo o ácido. No entanto, até onde pudemos constatar, não existe tal formulação disponível no mercado.

Um segundo ponto importante revelado pelos resultados de longo prazo, o ATA mostrou grau de complicações muito elevado. No segundo grupo, 26,6\% dos animais morreram após apresentarem contaminação da cavidade abdominal por lesão química. Além disso, 26,6\% tiveram sinais de lesão tecidual intensa que impossibilitaram a avaliação dos parâmetros propostos. A análise dos órgãos nos permite concluir que houve progressão do efeito do ATA, mesmo naqueles animais que clinicamente se mostravam estáveis a curto prazo e isso levou ao óbito. Embora nossos resultados sejam de certa forma surpreendentes, trazem à tona uma importante questão sobre o possível uso dessa substância em humanos. A experiência mostra que, apesar de ser habitualmente utilizado de modo bastante criterioso, o poder corrosivo do ATA pode causar lesões vaginais e cervicais e até mesmo quadro de estenose vaginal definitiva. Assim, nosso experimento tem valor no sentido de demonstrar que o uso de ATA como método de ablação endometrial constitui um risco potencial de lesão de estruturas nobres da mulher. 
Pode-se argumentar que a estrutura do útero humano é mais resistente, tendo espessura maior e não sofreria lesão na extensão da que foi demonstrada em nosso estudo. No entanto, até o momento as provas experimentais da segurança do método são extremamente escassas. Os estudos realizados em humanos avaliam apenas o aspecto clínico e as alterações endometriais locais a longo prazo. Nosso estudo mostra que o efeito de retardo do ATA não é desprezível e que lesões tardias podem ocorrer de maneira insidiosa o que pode levar à demora no diagnóstico e no tratamento das eventuais complicações.

Outro ponto positivo do nosso projeto é demonstrar que, apesar de se constituir em possível opção de método de ablação endometrial, o uso de ATA ainda carece de estudos para definir a dose, a formulação, o método de administração e até mesmo as complicações a longo prazo. Acreditamos que um dos problemas cruciais na transformação desse método como uma opção real de tratamento, seja o modo de liberação da substância e os efeitos teciduais a longo prazo. Obtendo-se uma formulação química em que a liberação seja limitada ou mesmo que produza ação circunscrita apenas às camadas funcional e basal do endométrio, cremos que o método teria maior possibilidade de ser usado na prática diária.

Uma preocupação adicional no uso desse método é o efeito a longo prazo no endométrio. Os estudos realizados em humanos não exploram, de forma aprofundada, esses efeitos. No entanto, também baseados nos estudos dermatológicos, sabe-se que os efeitos a longo prazo do ATA devem-se à uma reorganização de elementos estruturais e ao aumento do 
volume da derme como resultados do aumento do conteúdo de colágeno, glicosaminoglicanos e elastina ${ }^{28}$. Habitualmente, há um processo de reepitelização e renovação do epitélio a partir de estruturas anexiais preservadas da destruição. Nesse sentido, poderia se esperar que o endométrio também pudesse passar por processo de reepitelização e reorganização das estruturas destruídas, limitando assim seus efeitos como método de ablação endometrial definitivo. Infelizmente, nosso modelo não foi capaz de esclarecer essa questão, uma vez que as lesões foram de tal magnitude que inviabilizaram a análise. De maneira semelhante os estudos já efetuados em humanos não foram capazes de responder a essa questão.

Por fim, acreditamos que, com base nos objetivos desenhados para esse estudo, fomos capazes de responder à maioria das questões formuladas e trazer informações que podem ser úteis no estudo desse método de ablação endometrial. 
6. CONCLUSÕES 


\section{CONCLUSÕES}

As conclusões obtidas com a presente pesquisa foram:

- O estudo permitiu o desenvolvimento de um modelo viável de ablação endometrial em ratas adultas;

- As alterações histológicas e histomorfométricas encontradas nos cornos uterinos mostraram que o ácido tricloroacético é um potente agente na destruição química do endométrio em modelo animal;

- No modelo apresentado, não foi observada regeneração endometrial após o retorno ao ciclo estral. 
7. ANEXOS

ב 


\section{ANEXOS}

\section{Anexo 1. Fluxograma do projeto}

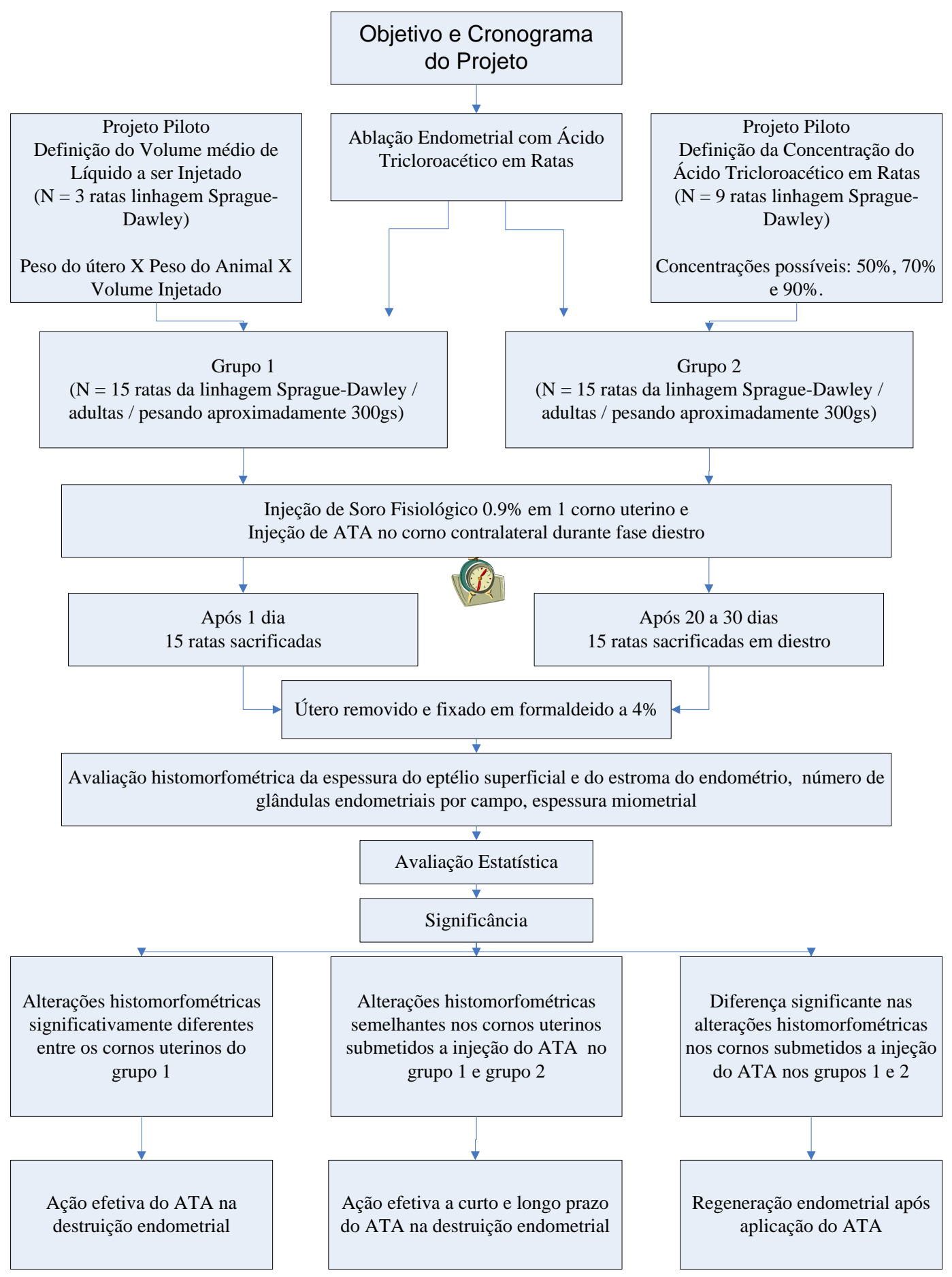




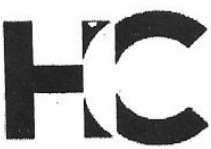

Ao

Depcitamento de Obstetrícia e Ginecologia

A Comissão de Ética para Análise de Projetos de Pesquisa - CAPPesq da Diretoria Clínica do Hospital das Clínicas e da Faculdade de Medicina da Universidade cie São Paulo, em sessão de 03/06/09 tomou conhecimento que 0 Frotocolo de Pesquisa $n^{\circ}$ 0629/07 intitulado: "Ablação Endomeirial cưm Ácioio Tricloroacético em Rałas" será dissertação de mestrado da aluna MARIANA AMORA COCUZZA, tendo corno orientador DR. GUSTAVO ARANTES ROSA MACIEL.

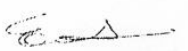

PROF. DR. EDUARDO MASSAD

Presidente da Comissão Ética para Análise de Projetos de Pesquisa

Comissão de Ética para Análise de Projetos de Pesquisa do HCFMUSP e da FMUSP Diretoria Clínica do Hospital das Clínicas da Faculdade de Medicina da Universidade de São Paulo Rua Ovidio Pires de Campos. $2255^{\circ}$ andar - CEP 05430010 - São Paulo - SP
Fone: 011 - 30696442 fax: 011 - 30696492 - e-mail: cappesq@hcnet.usp.br / secretariacappesq2@hcnet.usp.br 
8. REFERÊNCIAS 


\section{REFERÊNCIAS}

1. Hallberg, L, Hogdahl, AM, Nilsson, L, Rybo, G. Menstrual blood loss--a population study. Variation at different ages and attempts to define normality. Acta Obstet Gynecol Scand. 1966;45(3):320-51.

2. Kucuk, M, Okman, TK. Intrauterine instillation of trichloroacetic acid is effective for the treatment of dysfunctional uterine bleeding. Fertility and sterility. 2005;83(1):189-94.

3. Gath, D, Osborn, M, Bungay, G, lles, S, Day, A, Bond, A, et al. Psychiatric disorder and gynaecological symptoms in middle aged women: a community survey. Br Med J (Clin Res Ed). 1987;294(6566):213-8.

4. Ferenczy, A, Bergeron, C. Histology of the human endometrium: from birth to senescence. Annals of the New York Academy of Sciences. 1991;622:6-27.

5. Christiaens, GC, Sixma, JJ, Haspels, AA. Hemostasis in menstrual endometrium: a review. Obstetrical \& gynecological survey. 1982;37(5):281-303.

6. Kirkland, JL, Murthy, L, Stancel, GM. Progesterone inhibits the estrogeninduced expression of c-fos messenger ribonucleic acid in the uterus. Endocrinology. 1992;130(6):3223-30.

7. Fraser, IS, Hickey, M, Song, JY. A comparison of mechanisms underlying disturbances of bleeding caused by spontaneous dysfunctional uterine bleeding or hormonal contraception. Human reproduction (Oxford, England). 1996;11 Suppl 2:165-78. 
8. Shaw, RW. Assessment of medical treatments for menorrhagia. $\mathrm{Br} \mathrm{J}$ Obstet Gynaecol. 1994;101 Suppl 11:15-8.

9. Sculpher, MJ, Dwyer, N, Byford, S, Stirrat, GM. Randomised trial comparing hysterectomy and transcervical endometrial resection: effect on health related quality of life and costs two years after surgery. Br J Obstet Gynaecol. 1996;103(2):142-9.

10. Bachmann, GA. Hysterectomy. A critical review. I Reprod Med. 1990;35(9):839-62.

11. Farquhar, CM, Steiner, CA. Hysterectomy rates in the United States 19 90-1997. Obstetrics and gynecology. 2002;99(2):229-34 .

12. Johnson, N, Barlow, D, Lethaby, A, Tavender, E, Curr, E, Garry, R. Surgical approach to hysterectomy for benign gynaecological disease. Cochrane database of systematic reviews (Online). 2005;(1):CD003677.

13. Lethaby, A, Hickey, M, Garry, R. Endometrial destruction techniques for heavy menstrual bleeding. Cochrane database of systematic reviews (Online). 2005;(4):CD001501.

14. Nagele, F, O'Connor, H, Davies, A, Badawy, A, Mohamed, H, Magos, A. 2500 Outpatient diagnostic hysteroscopies. Obstetrics and gynecology. 1996;88(1):87-92.

15. Goldrath, MH, Fuller, TA, Segal, S. Laser photovaporization of endometrium for the treatment of menorrhagia. Am J Obstet Gynecol. 1981;140(1):14-9.

16. El-Nashar, SA, Hopkins, MR, Creedon, DJ, St Sauver, JL, Weaver, AL, McGree, ME, et al. Prediction of treatment outcomes after global endometrial ablation. Obstetrics and gynecology. 2009;113(1):97-106. 
17. Pooley, AS, Ewen, SP, Sutton, CJ. Does transcervical resection of the endometrium for menorrhagia really avoid hysterectomy? Life table analysis of a large series. J Am Assoc Gynecol Laparosc. 1998;5(3):22935.

18. Overton, C, Hargreaves, J, Maresh, M. A national survey of the complications of endometrial destruction for menstrual disorders: the MISTLETOE study. Minimally Invasive Surgical Techniques--Laser, EndoThermal or Endorescetion. $\mathrm{Br} J$ Obstet Gynaecol. 1997;104(12):1351-9.

19. Glasser, MH. Practical tips for office hysteroscopy and second-generation "global" endometrial ablation. Journal of minimally invasive gynecology. 2009;16(4):384-99.

20. Lethaby, A, Hickey, M, Garry, R, Penninx, J. Endometrial resection / ablation techniques for heavy menstrual bleeding. Cochrane database of systematic reviews (Online). 2009;(4):CD001501.

21. Bourdrez, P, Bongers, MY, Mol, BW. Treatment of dysfunctional uterine bleeding: patient preferences for endometrial ablation, a levonorgestrelreleasing intrauterine device, or hysterectomy. Fertility and sterility. 2004;82(1):160-6, quiz 265.

22. Ling, MR. Therapy of genital human papillomavirus infections. Part I: Indications for and justification of therapy. Int $J$ Dermatol. $1992 ; 31(10): 682-6$.

23. Sowter, MC, Lethaby, A, Singla, AA. Pre-operative endometrial thinning agents before endometrial destruction for heavy menstrual bleeding. Cochrane database of systematic reviews (Online). 2002;(3):CD001124. 
24. Donnez, J, Vilos, G, Gannon, MJ, Maheux, R, Emanuel, MH, Istre, O. Goserelin acetate (Zoladex) plus endometrial ablation for dysfunctional uterine bleeding: a 3-year follow-up evaluation. Fertility and sterility. 2001;75(3):620-2.

25. Kucukozkan, T, Kadioglu, BG, Uygur, D, Moroy, P, Mollamahmutoglu, L, Besli, M. Chemical ablation of endometrium with trichloroacetic acid. International journal of gynaecology and obstetrics: the official organ of the International Federation of Gynaecology and Obstetrics. 2004;84(1):41-6.

26. O'Neil, M. The Merck Index:An Encyclopedia of Chemicals, Drugs, and Biologicals. 14 ed 2006.

27. Scheinfeld, N, Lehman, DS. An evidence-based review of medical and surgical treatments of genital warts. Dermatology online journal. 2006;12(3):5.

28. Butler, PE, Gonzalez, S, Randolph, MA, Kim, J, Kollias, N, Yaremchuk, MJ. Quantitative and qualitative effects of chemical peeling on photo-aged skin: an experimental study. Plastic and reconstructive surgery. 2001;107(1):222-8. 